\title{
Sensing their plasma membrane curvature allows migrating cells to circumvent obstacles
}

\author{
Ewa Sitarska1,§, Silvia Dias Almeida ${ }^{1, \ddagger}$, Marianne Sandvold Beckwith¹, Julian Stopp², \\ Yannick Schwab ${ }^{1}$, Michael Sixt ${ }^{2}$, Anna Kreshuk ${ }^{1}$, Anna Erzberger ${ }^{1}$ and Alba Diz- \\ Muñoz ${ }^{1, *}$
}

\author{
Addresses \\ 1 Cell Biology and Biophysics Unit, European Molecular Biology Laboratory, 69117 Heidelberg, \\ Germany. \\ ${ }^{2}$ Institute of Science and Technology Austria, 3400 Klosterneuburg, Austria. \\ $\S$ Collaboration for joint PhD degree between EMBL and Heidelberg University, Faculty of Biosciences. \\ $\ddagger$ Current address: Division of Medical Image Computing, German Cancer Research Center (DKFZ), \\ 69120 Heidelberg, Germany. \\ * Correspondence: diz@embl.de.
}

\begin{abstract}
To navigate through tissues, migrating cells must balance persistent migration with changes in direction to circumvent obstacles. The protrusion at the leading edge of a moving cell is driven by actin polymerization and displays dynamic membrane patterns that constantly probe the environment. Here, we asked whether cells read out their membrane topography to decode their environment and decide if they should move ahead or turn away. To test this, we first parametrized the curvature of the plasma membrane of migrating immune cells to match microscopy data. Then, we created a theoretical model to explore what types of feedback between topography and protrusion could lead to the observed patterns. Our model predicts that negative coupling of positive (inward) curvature of the plasma membrane to actin polymerization would explain our data. To identify the putative positive curvature sensor, we screened for proteins with suitable membrane binding domains that are expressed during cell migration. We found that the BAR domain protein Snx33 localized to the leading edge, and destabilized it by inhibiting the major actin nucleation promoting factor WAVE2. This mechanism was indeed required for navigation, as Snx33 knockout cells fail to change direction when hitting inert or cellular obstructions but continued to migrate persistently. Our results show how cells can read out their surface topography to interpret their environment, allowing them to rapidly switch between persistent and exploratory migration in order to circumvent obstacles.
\end{abstract}




\section{Main text:}

Cell migration drives many developmental, physiological, and pathological processes. While the mechanisms underlying propulsion are largely known, it remains unclear how cells steer their movement to navigate complex and dynamic environments ${ }^{1}$ and circumvent obstacles within tissues ${ }^{2,3}$. These adaptive behaviors are particularly important for cell types that require fast and dynamic responses, such as immune cells and disseminating tumor cells. Switching between actin-driven protrusions and blebbing has been shown to aid cell steering in development ${ }^{4}$, but cells often only display actin-rich cell protrusions such as lamellipodia and ruffles. These need to be long-lived enough for cells to explore and then persistently move through their surroundings, while 'unstable' enough to allow them to adapt and change direction when confronted with an obstacle ${ }^{5,6}$. The dynamic nature of these protrusions leads to dramatic changes in plasma membrane curvature, especially at the leading edge (5, Fig. 1a, b). However, it remains unclear whether membrane curvature encodes information that cells use to choose their migration path 7,8 , or if membrane topography is only a side-effect of the forces acting at the cell surface. In particular, we wondered if a direct feedback between membrane curvature and actin-driven propulsion might underlie adaptive migration behaviours. Indicative of such feedback effects, many immune cells display characteristic wave-like patterns at their leading edge,6,9-11.

To investigate this hypothesis, we made use of immune-like cells (HL-60 cells), which polarize and continuously rearrange their membrane curvature independently of cell adhesion, thus allowing us to test the role of intrinsic changes in plasma membrane curvature for cell motility6,12. We terminally differentiated HL-60 cells in vitro to generate motile neutrophil-like cells from stationary round blasts (Fig. 1c, Supplementary Fig. 1a). When induced to differentiate, these cells undergo substantial changes in gene expression and initiate rapid migration, resembling what occurs in the bone marrow in vivo $^{13}$. The terminally differentiated, motile cells ( $\mathrm{dHL}-60$ cells) display both actin-rich lamellipodia and membrane ruffles at the leading edge. To analyze membrane topography in more detail, we used scanning electron microscopy (SEM), for ultrastructural detail of natively fixed cell membranes, and polarized total internal reflection fluorescence microscopy ( $p$-TIRFM), which enables probing membrane curvature dynamics in live cells. We observed curved membrane patterns, as observed by SEM in the upper plasma membrane (Fig. 1b), that are very dynamic, as visualized by $p$-TIRFM in the basal plasma membrane (Fig. 1d, Supplementary Fig. 1b-d).

To predict what could generate the observed patterns, we performed a general theoretical analysis and mapped out how actin-dependent force generation and membrane curvature could be coupled to generate these dynamic patterns at the leading edge. We found that a spontaneous pattern emerges only when there is a negative coupling between curvature and actin activity (Supplementary Note), such that actin polymerization would decrease in regions of inward (positive) plasma membrane curvature (Fig. 1e). In more molecular terms, these theoretical results indicate that the coordinate action of sensing positive membrane curvature and locally down-regulating actin polymerization can lead to an instability in the lamellipodium that would generate the dynamic patterns at the leading edge of migrating cells, as those we observed in neutrophils.

To test if such a molecular feedback is present, we set out to identify a positive curvature sensor that would act during migration. One protein family that could facilitate membrane curvature sensing is BAR domain-containing proteins. These proteins form crescent-shaped membrane-binding dimers that can sense and generate curvature ${ }^{14-16}$. Notably, their key roles in membrane remodeling and organelle trafficking are facilitated by modulation of the actin cytoskeleton through several auxiliary domains (e.g. SH3, RhoGAP, RhoGEF, PX, PH) that regulate membrane binding and nucleation promoting factors of the Arp2/3 complex, formins, or Rho GTPases ${ }^{16,17}$. To identify candidates from this large protein family, we measured their expression profile before and after $\mathrm{HL}-60$ differentiation to a migratory state, i.e., in a curvature-poor versus a curvature-rich state. The BAR domain protein Snx33 was 16-fold overexpressed in the curvature-rich state (Fig. 1f). It contains a positively charged patch, which strongly suggests an inward (positive) curvature-dependent binding (Fig. 1g, Supplementary Fig. 2a-d). Consistent with this, Snx33 has been predicted to bind shallow curvatures in comparison to many other 
BAR domain proteins ${ }^{16}$. Finally, we imaged its subcellular localization by confocal microscopy after fluorescent tagging and indeed found that $\mathrm{Snx} 33$ is enriched at membrane ruffles (Fig. $\mathbf{1 h}, \mathbf{i}$ ).

If Snx33 is indeed the sensor of membrane curvature that inhibits actin to destabilize the leading edge, it should be required for adaptive migratory behaviors. To test this, we generated a Snx33 knockout (Snx33 /-) cell line using CRISPR/Cas9 genome editing (Supplementary Fig. 3a, b) and given that cell shape reflects changes in motion-driving actin-rich protrusions ${ }^{18}$, we performed a quantitative and unbiased comparison of selected cell morphometric parameters, i.e., cell spreading, cell eccentricity and leading edge characteristics. As immune cells radically change their morphology in short periods of time, we performed our analysis over time, with the aim of capturing these dynamics. To this end, we trained and used machine learning-based algorithms in ilastik to analyze movies of cells imaged by total internal reflection fluorescence microscopy (TIRFM) (see Methods for details). Indeed, Snx33 -/- cells spread to a larger extent, showed a more elongated morphology and bigger leading edge (Fig. 2a-f, Supplementary Fig. 4a-e), migration phenotypes that were independent of cell adhesion (Supplementary Fig. 4f-h). Moreover, the increases in spread area and leading edge area could be rescued by expressing fluorescently-tagged Snx33 proving specificity of the observed phenotypes (Supplementary Fig. 4b, c). Altogether, these results indicate that Snx33 -/- cells have a more stable leading edge during migration, consistent with the predicted role of this BAR domain protein.

Leading edge growth and increased cell spreading during persistent migration is known to increase plasma membrane tension ${ }^{19,20}$. To test if the more stable leading edge induced by loss of Snx33 leads to higher membrane tension, we measured it by static tether pulling with atomic force spectroscopy, where a plasma membrane tether is held with a constant length until it breaks. We found that apparent membrane tension increases by almost 50\% in Snx33 \%- cells (from 177.87 to $265.62 \mu \mathrm{N} / \mathrm{m}$; see Methods for details; Supplementary Fig. 5a, b). Moreover, the increases in membrane tension could be rescued by stably expressing fluorescently-tagged Snx33, excluding Snx33-independent functions as the origin of these phenotypes (Supplementary Fig. 5b, c). Last, overexpression of Snx33-GFP on the wt background did not decrease membrane tension, suggesting that a gain of function is not sufficient to alter the leading edge or its effects on membrane mechanics (Supplementary Fig. 5d). These results further confirm that Snx33 /- cells have a more stable leading edge showing all characteristics expected for persistent migration. Notably, these phenotypes were not a consequence of defective differentiation, as the neutrophil differentiation marker CD11b was unperturbed in Snx33 -/- cells (Supplementary Fig. 3c).

These data are compatible with the hypothesis that Snx33 negatively regulates actin polymerization in areas of inward curvature and thereby limits leading edge size. Several BAR domain proteins, including Snx33, directly bind and regulate the activity of actin nucleator promoting factors from the WASP family ${ }^{16,21}$. WAVE2 is the main member of this family in neutrophils and earned its name because it localizes in a wave pattern on the basal membrane during cell migration ${ }^{10}$. What regulates WAVE2 binding to the membrane and determines its characteristic localization pattern remains poorly understood 22. In our theoretical model, the pattern of membrane curvature and actin activator (such as WAVE2) emerge due to mechanochemical feedback (Fig. 1e) and the pattern wavelength is predicted to increase if the curvature coupling is reduced, which should lead to wider WAVE2 patches (Fig. 3a). To test this prediction, we imaged WAVE2 patterns in Snx33 -/- and wild-type cells during migration by TIRFM (Fig. 3b-d). Strikingly, Snx33 /- cells showed an increase in both the length and the width of WAVE2 patches (Fig. 3e, Supplementary Fig. 6a, b). This is particularly interesting as, to date, only very drastic WAVE2 patch phenotypes have been reported (complete abrogation or increase in number), which lead to severely disrupted capacity to migrate 23,24 . Our model predicts that this change in WAVE2 patch morphology should accompany a longer wavelength of the curved ruffles on the plasma membrane (Fig. 3a). To test this, we quantified the effective ruffle wavelength from SEM images and indeed observed a significantly less tight arrangement of ruffles for Snx33 -/- cells when compared with their wild-type counterparts (Fig. 3f, g, Supplementary Fig. 4i, Supplementary Fig. 6c). These findings identify Snx33 as a key component in the feedback between membrane shape and the actin polymerization factors that modulate it. They provide the molecular pathway to the prediction from our 
theoretical model, namely that coupling the sensing of positive membrane curvature with local downregulating of actin polymerization is sufficient to generate complex patterns at the leading edge of migrating cells.

Our data thus far reveal an unexpected role for the membrane curvature binding protein Snx33 in regulating actin polymerization and leading edge morphology. But does this function play a role in steering cell migration $25-27$ ? To dissect that, we first followed dHL-60 cells during unconfined migration on 2D substrates with a homogeneous chemoattractant, promoting cell motility without requiring the cells to adapt to any obstacle. By measuring speed and turning angles we could show that Snx33 -/- cells migrated faster and in a more persistent manner in a decision-free 2D environment, while wild-type cells were more prone to turn (Fig. $\mathbf{4 a - C )}$ ). This more persistent migration in the absence of Snx33 is consistent with the increase in leading edge size and plasma membrane tension we observed in Snx33 -/- cells (Fig. 2d-f, Supplementary Fig. 5b).

Migration through diverse tissues requires cells to circumvent obstacles and protrusion dynamics have been shown to increase during directional changes in 3D environments 5 . Our data thus far suggested that Snx33 promotes leading edge instabilities, which could facilitate object avoidance, because inward membrane deformations generated by collisions would locally down-regulate propulsion and thereby reorient the leading edge. To test this, we followed confined HL60 cell migration through microfluidic devices that contained obstacles ${ }^{28,29}$. As expected from the unconfined migration, Snx33 -/- dHL60 cells migrate more persistently in decision-free 3D environments (Supplementary Fig. 7a, b). However, in microfluidic devices where cells encounter obstacles in the form of differently sized pores, Snx33 -/- cells required significantly more time than their wild-type counterparts (Fig. 4d) to find the path of least resistance (Supplementary Fig. 7c, d). The less dynamic leading edge of Snx33 $/$ - cells therefore appears to make them less effective in circumventing an obstacle.

To gain further insights into the object-avoidance response of Snx33-deficient cells, we devised a reductionistic assay to test contact inhibition of locomotion (CIL), a common phenomenon to many cell types, including dHL-60s, where cells stop moving in a particular direction when they come into contact with another cell or an object ${ }^{10,30}$. To test if CIL as a response to cellular obstacles is controlled by Snx33, we seeded a higher density of dHL-60 cells imaged their 2D migration in the presence of cell-cell interactions by TIRFM. Snx33 -/- cells collided more often and formed larger cell-cell contacts compared to wild-type cells (Fig. 4e, f), in agreement with their increased decision time when faced with an inert obstacle (Fig. 4d). Finally, to gain molecular insight into the role of Snx33 in CIL, we simultaneously imaged the neutrophil WAVE2 complex (using Hem1) and Snx33 at the leading edge of live cells. While both proteins largely colocalized in most of the cell, they were anticorrelated in the highly negatively (outward) curved leading edge (Supplementary Fig. 8a, b). Here, Snx33 levels decreased while WAVE2 accumulated (Supplementary Fig. 8c, d), consistent with Snx33 binding positive curvature and restricting WAVE to negatively curved areas. Moreover, when cells collided, Snx33 localized to the cell contact area that is largely devoid of outward curvature, where subsequently WAVE2 disappeared and relocated to contact free zones of the plasma membrane. This resulted in cell repolarization by formation of a new leading edge (Fig. $\mathbf{4 g}, \mathbf{h}$ ). To assess whether the dysfunctional CIL response in Snx33 -/- cells is indeed due to impaired WAVE2 inhibition at the contact area, we followed WAVE2 localization before and after collision in Snx33 -/- cells. In contrast to wildtype cells, without Snx33 cells indeed failed to remove WAVE2 from the contact site (Fig. 4i, Supplementary Fig. 8e).

To date, little is known about the molecular machinery orchestrating CIL, and in particular, no curvature sensing has yet been shown to regulate it. Our study shows a key role for membrane topography and the curvature sensing protein Snx33 in regulating actin polymerization during CIL, a process not only key for the migration of immune and cancer cells in complex tissue environments, but also fundamental during embryogenesis and collective migration in vivo31.

Here, by using immune-like cells, which polarize and generate a leading edge in an adhesionindependent manner, we take a cell centric approach to demonstrate a new role for membrane topography in de-stabilizing lamellipodia for efficient navigation. By analyzing the membrane topography 
bioRxiv preprint doi: https://doi.org/10.1101/2021.03.26.437199; this version posted May 16, 2021. The copyright holder for this preprint (which was not certified by peer review) is the author/funder, who has granted bioRxiv a license to display the preprint in perpetuity. It is made available under aCC-BY-NC-ND 4.0 International license.

of migrating immune-like cells we developed a theoretical model that predicts such patterns to emerge from negative coupling of membrane curvature to actin polymerization. Guided by this prediction we identify a curvature sensing protein expressed specifically during migration, Snx33, that senses inward (positive) curvature and inhibits actin polymerization by WAVE2, the main nucleation promoting factor in neutrophils. Thus, Snx33 limits the persistence of the leading edge by de-stabilizing lamellipodia when they hit an obstacle. We show that this is key for cells to avoid both inert and cellular obstacles and thereby navigate complex three-dimensional environments. The fact that a curvature sensing protein can tune leading edge dynamics shows that cells use their membrane topography to encode information about the external environment they encounter. Given the diversity of BAR domain proteins present in cells, we expect that this regulatory principle is likely to be used in many biological functions that have to react to shape changes, from the subcellular level (organelle homeostasis, membrane trafficking) via the single cell level (immune surveillance, tumor dissemination) to the multicellular level (gastrulation, tissue folding). 
bioRxiv preprint doi: https://doi.org/10.1101/2021.03.26.437199; this version posted May 16, 2021. The copyright holder for this preprint (which was not certified by peer review) is the author/funder, who has granted bioRxiv a license to display the preprint in perpetuity. It is made available under aCC-BY-NC-ND 4.0 International license.
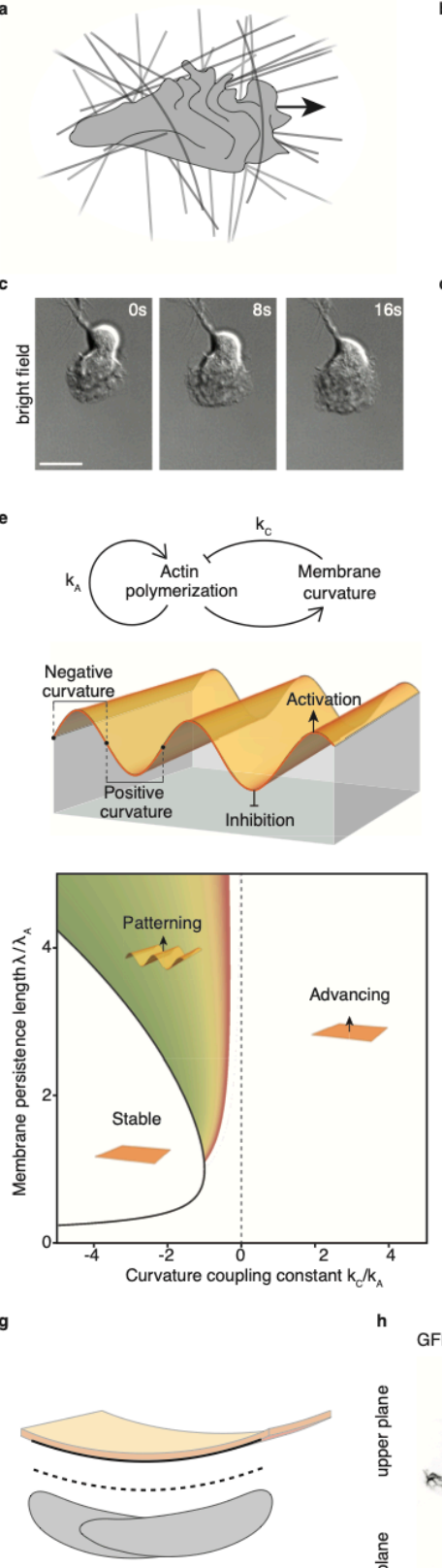
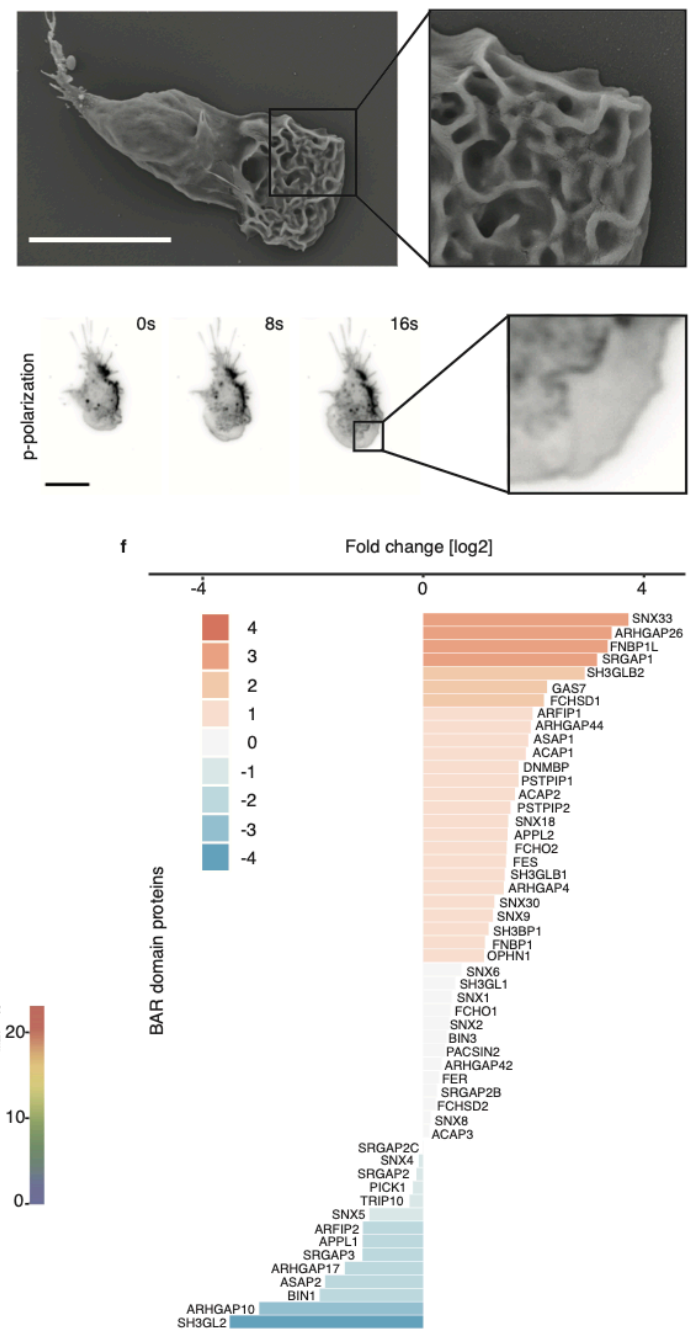

i

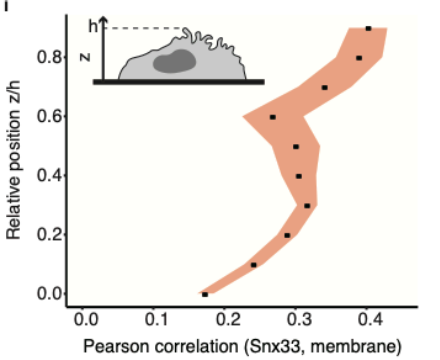

Figure 1: Curvature patterning in the lamellipodium and the curvature-sensitive protein Snx33. a) The leading edge of migrating cells is characterized by intricate curvature patterns. Arrow indicates the direction of cell movement. b) Scanning electron microscopy (SEM) of dHL-60 cell with zoom-in at the leading-edge. c) Time-lapse bright-field imaging of dHL-60 cells. d) Time-lapse p-polarization of p-TIRFM imaging of dHL-60 cell with zoom-in at the leading-edge. e) Coupling between membrane curvature and actin activity leads to pattern formation for negative coupling between actin activity and membrane curvature. Such mechanochemical instabilities are a hallmark of active surfaces ${ }^{32-36}$. Here, the instability is governed by the curvature coupling coefficient kc relative to the actin self-activation constant $\mathrm{k}_{\mathrm{A}}$. Patterning furthermore depends on the mechanical properties of the plasma membrane, characterized by the membrane persistence length $\lambda=(\kappa / \gamma)^{1 / 2}$, in which $\kappa$ is the bending rigidity and $\gamma$ is the surface tension of the plasma membrane, and the diffusion length $\lambda_{A}=\left(D / k_{A}\right)^{1 / 2}$ in which $D$ is the diffusion coefficient of actin activators. See Supplementary Note for details on the calculation. $\mathbf{f}$ ) Under-expressed (blue) and over-expressed (orange) BAR domain genes between undifferentiated (non-migratory, curvature-poor) and differentiated (migratory, curvature-rich) HL-60 cells. g) Schematic of a BAR domain protein binding inward (positive) membrane curvature. h) Fluorescently-tagged Snx33 and CAAX (membrane marker) in upper and lower z-planes in dHL-60 cell. i) Pearson correlation coefficient of fluorescently-tagged Snx33 and CAAX in relative position $\mathrm{z} / \mathrm{h}$ acquired by confocal microscopy with schematic illustrating experimental setup. $\mathrm{n}=10$. Orange regions denote standard error of the mean. Scale bars $=10 \mu \mathrm{m}$. 
bioRxiv preprint doi: https://doi.org/10.1101/2021.03.26.437199; this version posted May $16,2021$. The copyright holder for this preprint (which was not certified by peer review) is the author/funder, who has granted bioRxiv a license to display the preprint in perpetuity. It is made available under aCC-BY-NC-ND 4.0 International license.
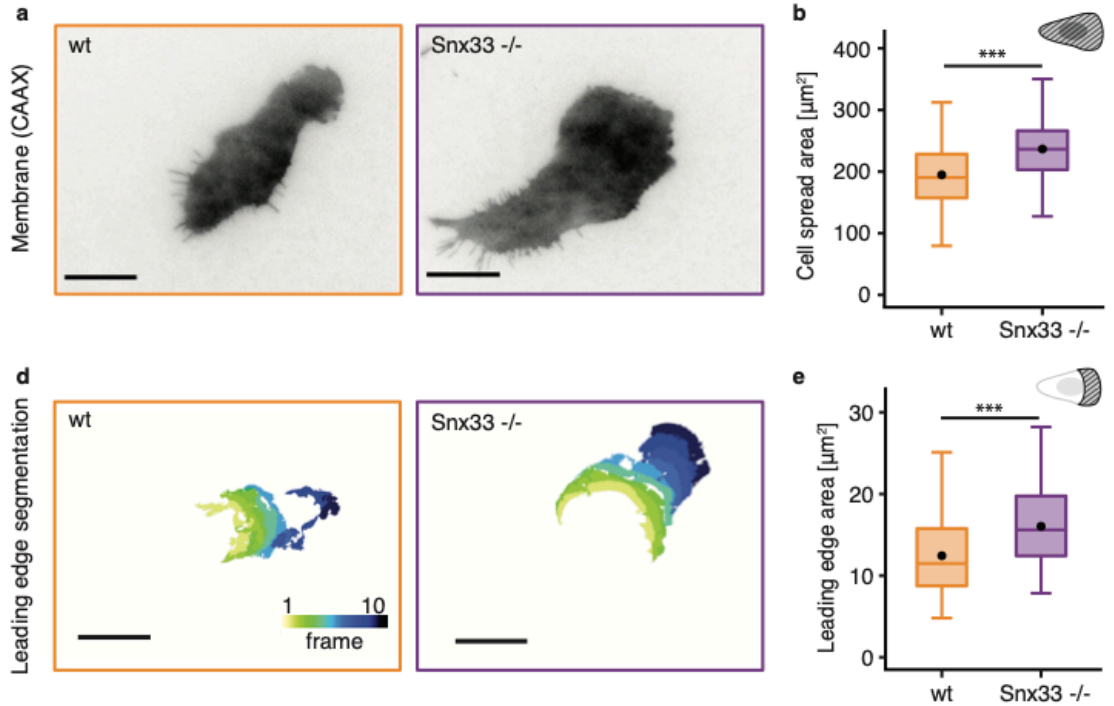
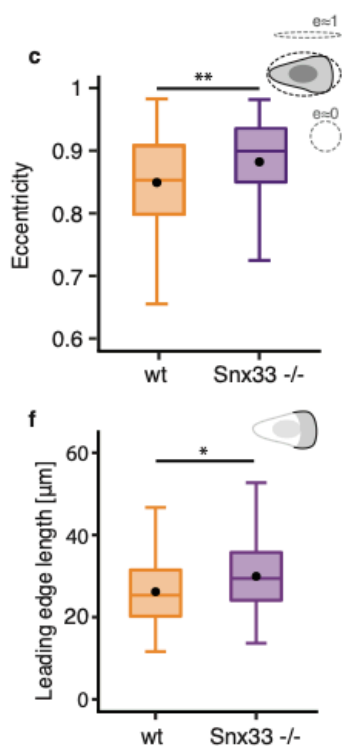

Figure 2: Snx33 knockout displays altered cell and leading-edge morphology. a) Exemplary wt and Snx33 -/dHL-60 cells imaged using TIRFM. b) Cell spread area and c) eccentricity based on time lapse analysis of dHL-60 cells using TIRFM. d) Exemplary evolution of the leading-edge segmentation of wt and Snx33 -/- dHL-60 cells. Time frames (5 s) is color-coded. e) Leading-edge area and f) length. $n=82$ (wt), $n=78$ (Snx33 -/-). Statistics: t-test or non-parametric Mann-Whitney-U-test. Scale bars $=10 \mu \mathrm{m} . \mathrm{p}<0.001\left(^{* * *}\right), p<0.01\left(^{* *}\right), p<0.05\left(^{\star}\right)$. 
bioRxiv preprint doi: https://doi.org/10.1101/2021.03.26.437199; this version posted May $16,2021$. The copyright holder for this preprint (which was not certified by peer review) is the author/funder, who has granted bioRxiv a license to display the preprint in perpetuity. It is made available under aCC-BY-NC-ND 4.0 International license.

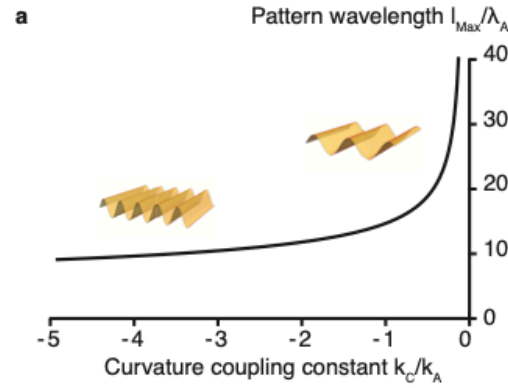

b
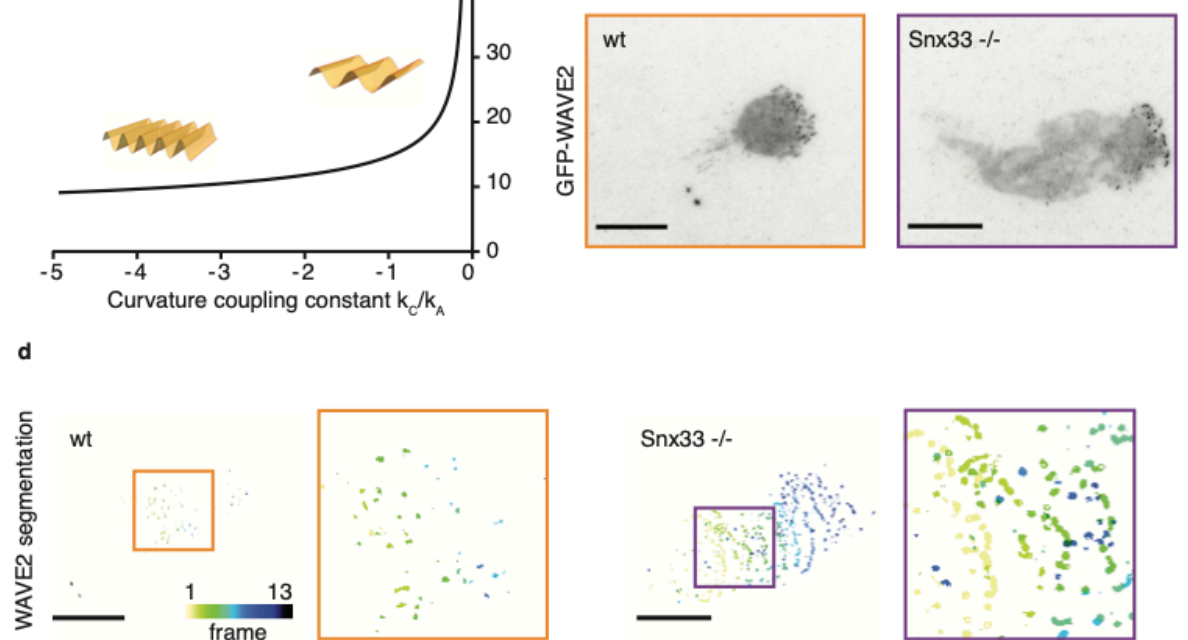

$\mathbf{f}$
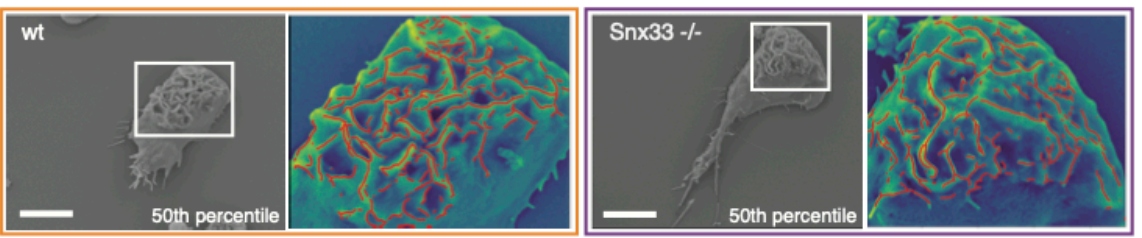

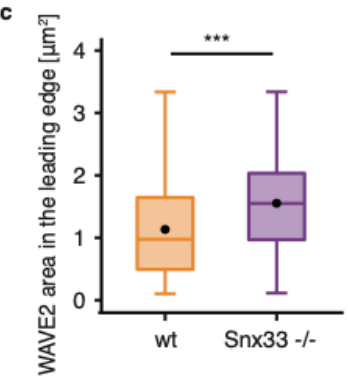

e

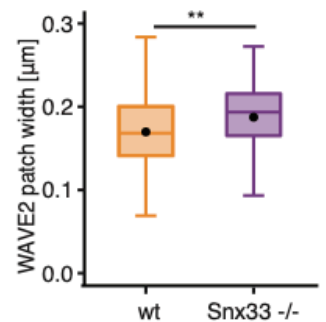

g

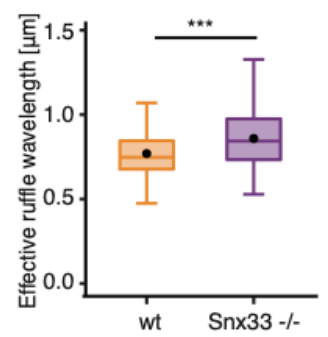

Figure 3: WAVE2 pattern width in Snx33 knockout increases as predicted by the model of mechanochemical patterning by curvature feedback. a) Our theoretical calculation predicts that the dominant wavelength $I_{\max }$ of the mechanochemical pattern in the lamellipodium should increase as the magnitude of the curvature coupling $k_{c}$ decreases. b) Exemplary images of Hem1-eGFP (component of the WAVE2 complex) in wt and Snx33 -/- dHL-60 cells using TIRFM. c) Quantification of WAVE2 area in the leading edge. d) Exemplary WAVE2 segmentation with zoom-in. Time frames (5 s) are color-coded. e) Quantification of WAVE2 patch width in wt and Snx33 -/- dHL-60 cells. $n=82$ (wt), $n=78$ (Snx33 -/-). f) SEM images (50th percentile) with zoom-in of the overlay of the leading-edge and ruffle segmentation (red) for wt and Snx33 -/- dHL-60 cells. g) Quantification of effective ruffle wavelength in wt and Snx33 -/- dHL-60 cells. $n=175$ (wt), $n=170$ (Snx33 -/-). Statistics: t-test or nonparametric Mann-Whitney-U-test. Scale bars $=10 \mu \mathrm{m} . \mathrm{p}<0.001\left(^{\star \star *}\right), p<0.01\left(^{\star \star}\right), p<0.05\left(^{\star}\right)$. 
bioRxiv preprint doi: https://doi.org/10.1101/2021.03.26.437199; this version posted May 16,2021 . The copyright holder for this preprint (which was not certified by peer review) is the author/funder, who has granted bioRxiv a license to display the preprint in perpetuity. It is made available under aCC-BY-NC-ND 4.0 International license.

a

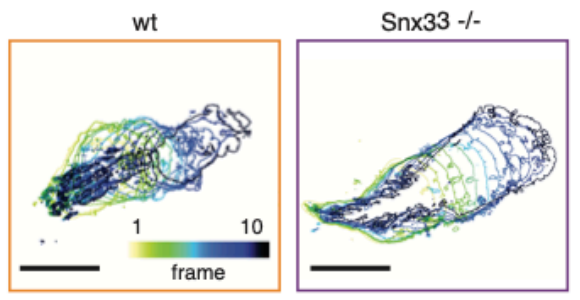

b

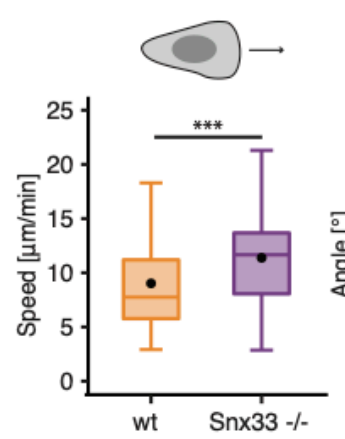

c

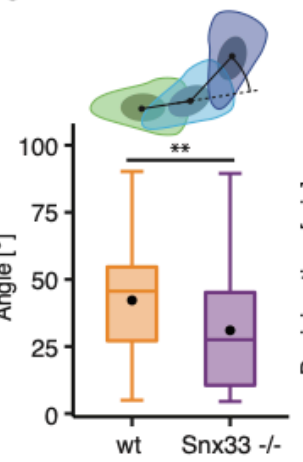

d

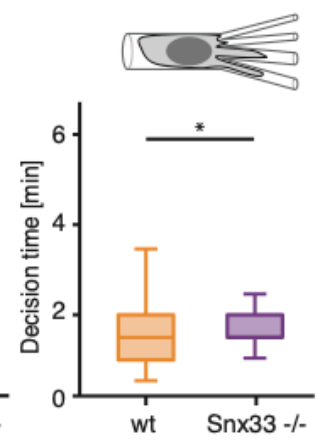

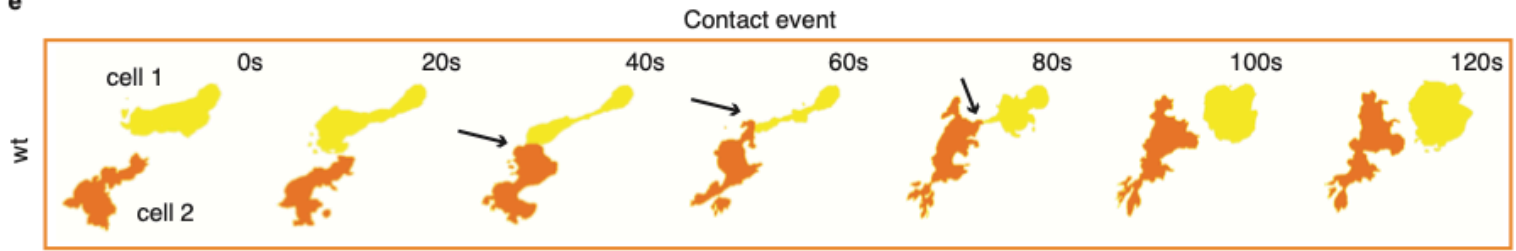

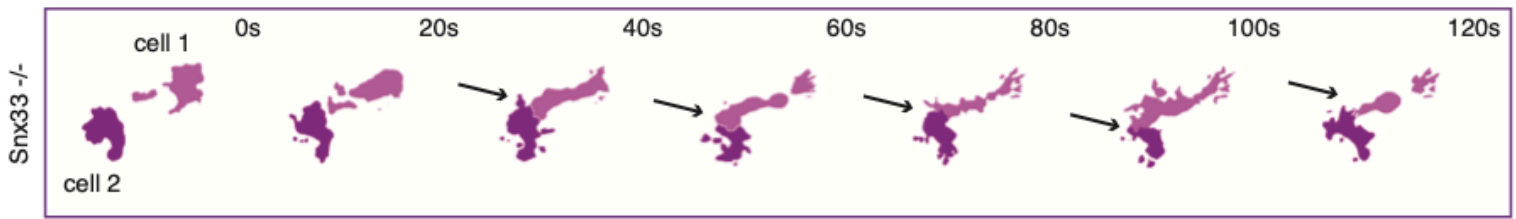

f

g

h

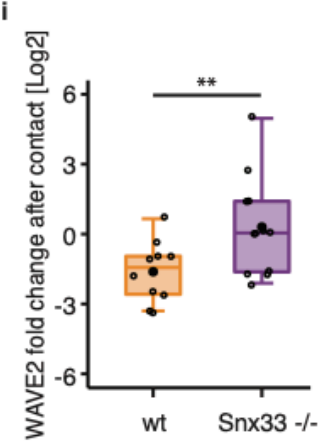

Figure 4: Snx33 steers cell movement in single-cell 2D and 3D migration by inhibiting the WAVE2 complex. a) Evolution of cell body displacement over time in wt and Snx33 -/- dHL-60 cells. Time frames (5 s) are colorcoded. b) Cell speed in wt and Snx33 -/- dHL-60 cells and c) distribution of angles at which dHL-60 cells turn during migration. $n=82(w t), n=78$ ( $S n \times 33-/-)$. d) Decision channel passage time $(n=159$ for wt, $n=91$ for $S n \times 33-/-)$ in $d H L-$ 60 cells. e) Segmentation of a contact event between two wt (upper panel) or Snx33 -/- (lower panel) dHL-60 cells. Arrows are pointing towards contact interfaces. f) Percentage of cell circumference in contact with another cell in wt $(n=18)$ and Snx33 -/- $(n=20)$ dHL-60 cells. g) Bright-field and h) TIRFM imaging of cell-cell contact in wt dHL-60 cells with fluorescently-tagged Snx33 and Hem1. Arrow is pointing towards cell-cell contact. i) WAVE2 fold change after cell-cell contact in wt $(n=9)$ and $S n \times 33-/-(n=10)$ dHL-60 cells. Statistics: t-test or non-parametric MannWhitney-U-test. Scale bars $=10 \mu \mathrm{m}$. Scale bars $=10 \mu \mathrm{m} . \mathrm{p}<0.001\left(^{* \star *}\right), \mathrm{p}<0.01\left(^{* \star}\right), \mathrm{p}<0.05\left(^{*}\right)$. 
bioRxiv preprint doi: https://doi.org/10.1101/2021.03.26.437199; this version posted May 16, 2021. The copyright holder for this preprint (which was not certified by peer review) is the author/funder, who has granted bioRxiv a license to display the preprint in perpetuity. It is made available under aCC-BY-NC-ND 4.0 International license.

a

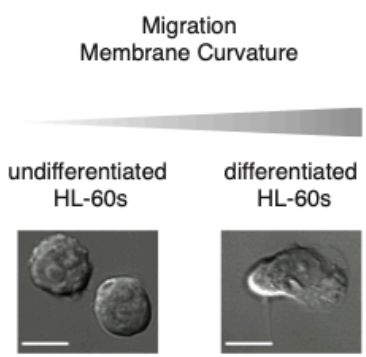

C
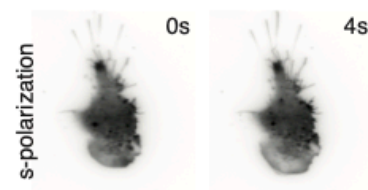

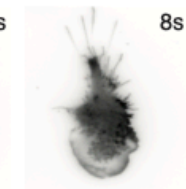

$8 s$

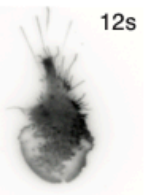

$12 \mathrm{~s}$

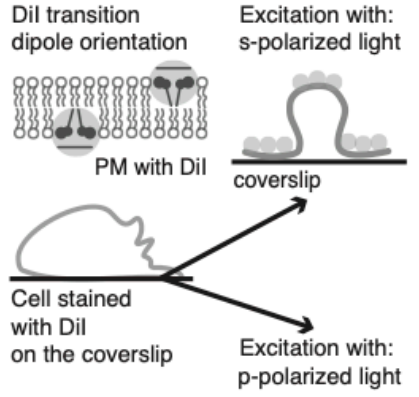

d

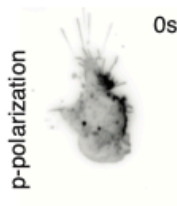

os

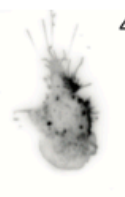

4s

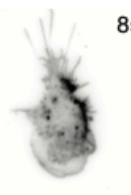

$8 s$

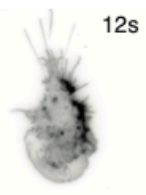

$16 s$

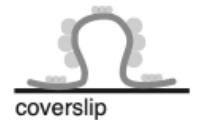

$16 \mathrm{~s}$

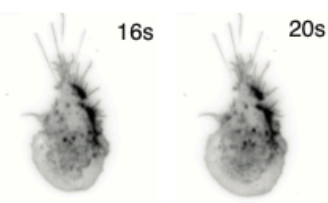

Supplementary Figure 1: Membrane topography imaged by pTIRFM. a) Schematic illustrating changes in HL-60 cells during its differentiation. b) Schematic illustrating the principles of pTIRFM imaging using carbocyanine dyes (Dil). Time lapse pTIRFM imaging of a dHL-60 cell using c) s-polarization and d) p-polarization. Scale bars $=10$ $\mu \mathrm{m}$. 
bioRxiv preprint doi: https://doi.org/10.1101/2021.03.26.437199; this version posted May 16, 2021. The copyright holder for this preprint (which was not certified by peer review) is the author/funder, who has granted bioRxiv a license to display the preprint in perpetuity. It is made available under aCC-BY-NC-ND 4.0 International license.

a

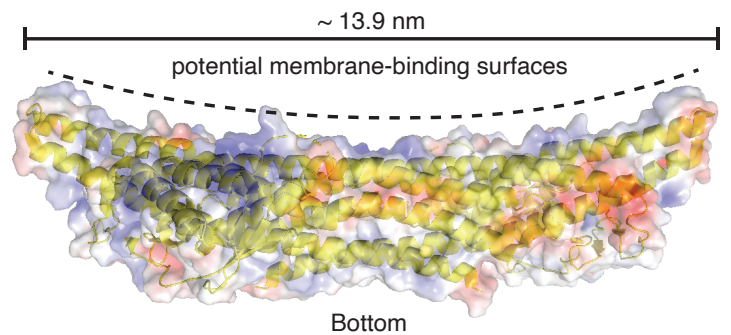

c

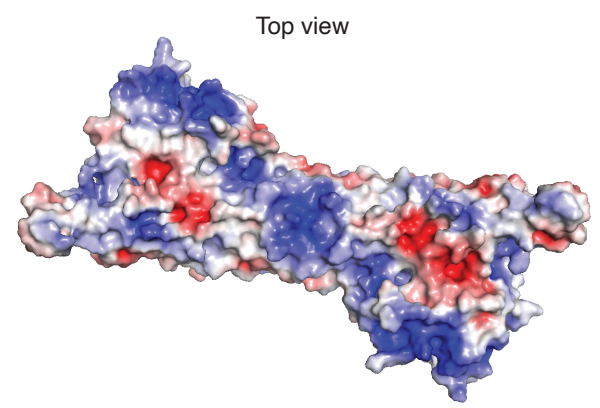

b

Side view

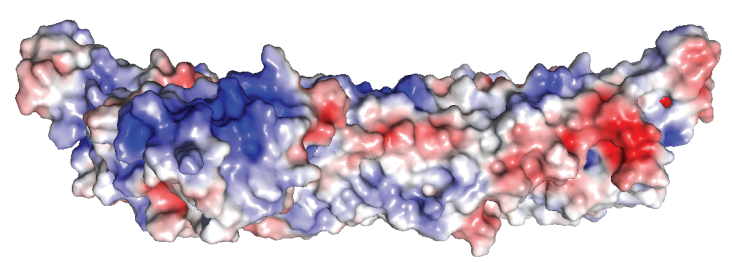

d Bottom view

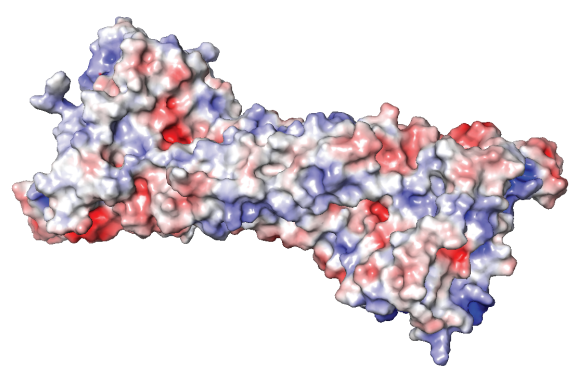

Positive

Supplementary Figure 2: Structure of Snx33 membrane binding unit (PX-BAR) strongly suggests binding to inward (positive) membrane curvature. a) Structure of PX-BAR domains of Snx33 (4AKV) together with electrostatic surface representation (side view). Dotted line indicates the potential membrane-binding surfaces, while solid line shows overall dimensions of the dimer. b-d) Electrostatic surface representation of 4AKV side view (b), top view (c) and bottom view (d). Visualizations were created in PyMOL (The PyMOL Molecular Graphics System, Version 2.4.2 Schrödinger, LLC). 
bioRxiv preprint doi: https://doi.org/10.1101/2021.03.26.437199; this version posted May 16,2021 . The copyright holder for this preprint (which was not certified by peer review) is the author/funder, who has granted bioRxiv a license to display the preprint in perpetuity. It is made available under aCC-BY-NC-ND 4.0 International license.

a

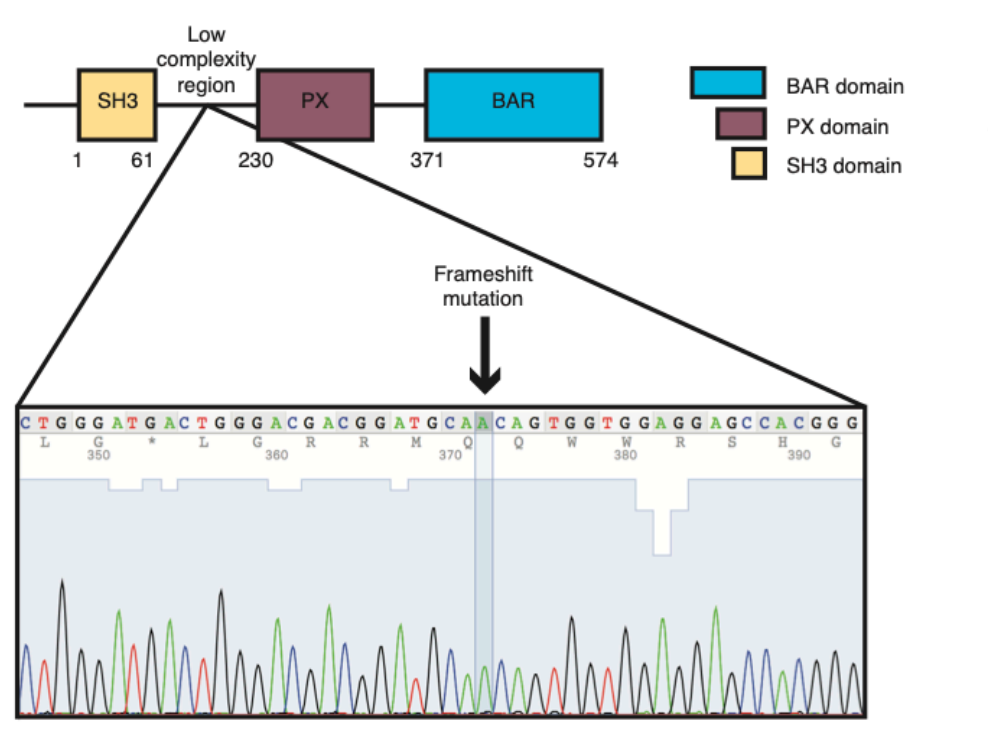

c

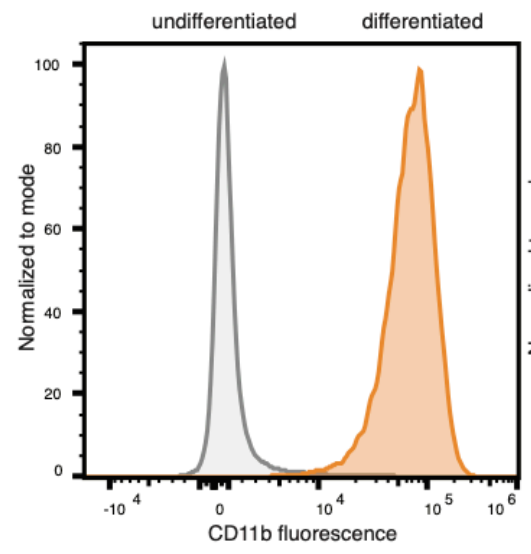

Snx33 -/-

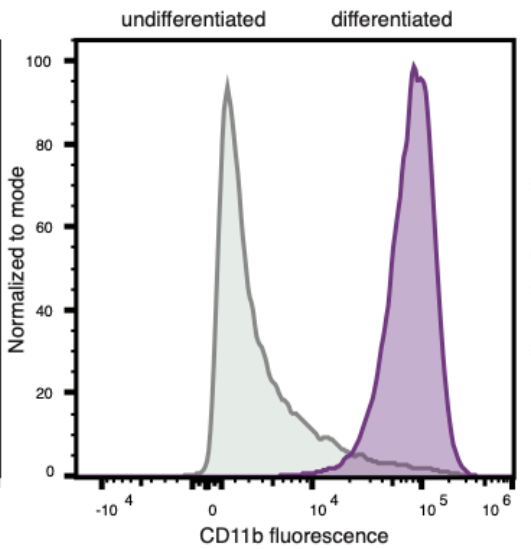

b

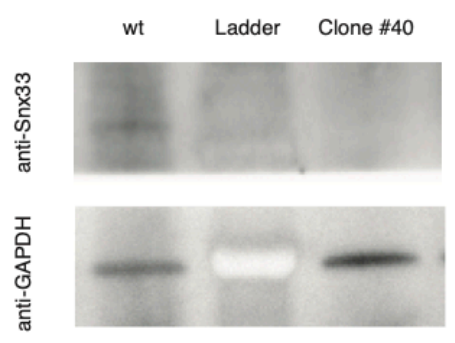

CRISPR/Cas9 control

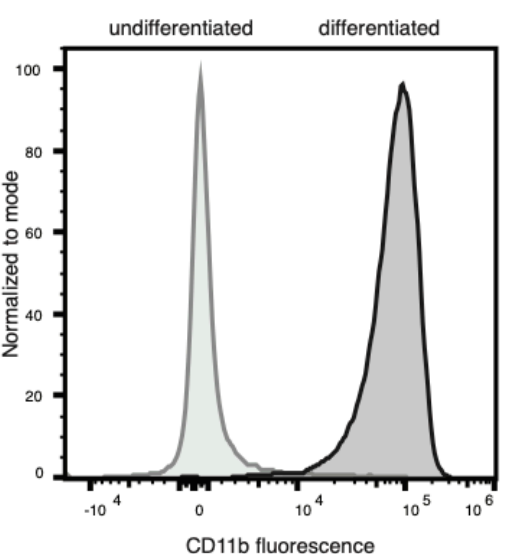

Supplementary Figure 3: Snx33 knockout cell line validation. a) Snx33 clone sequencing confirming a frameshift mutation. b) Snx33 and GAPDH Western blots of wt cells and Snx33 -/- clone. c) Representative histograms of CD11b intensity of wild-type, Snx33 -/- and CRISPR/Cas9 control of HL-60 cells before and after 5 days of differentiation. 
bioRxiv preprint doi: https://doi.org/10.1101/2021.03.26.437199; this version posted May $16,2021$. The copyright holder for this preprint (which was not certified by peer review) is the author/funder, who has granted bioRxiv a license to display the preprint in perpetuity. It is made available under aCC-BY-NC-ND 4.0 International license.

a
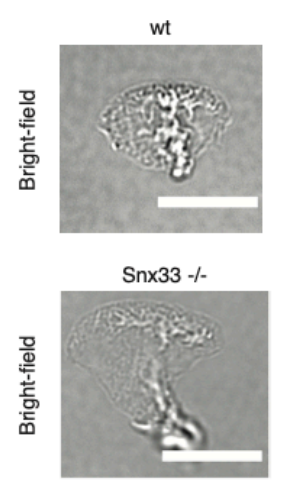

$\operatorname{Snx} 33 \%$ + eGFP-Snx33

$\frac{0}{\frac{0}{0}}$
$\frac{0}{5}$
$\frac{5}{5}$
$\frac{0}{5}$

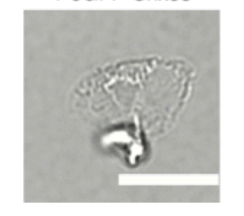

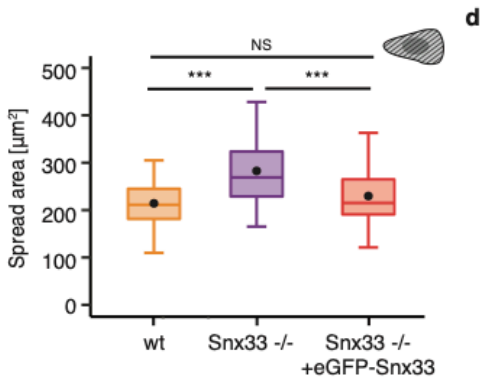

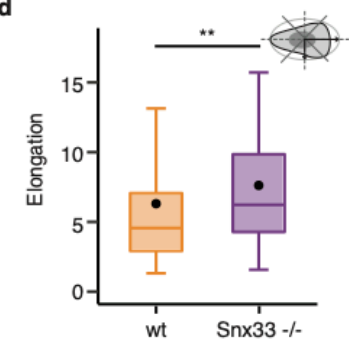

e

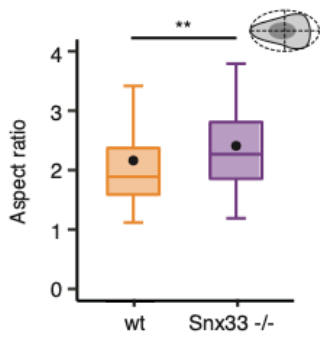

f

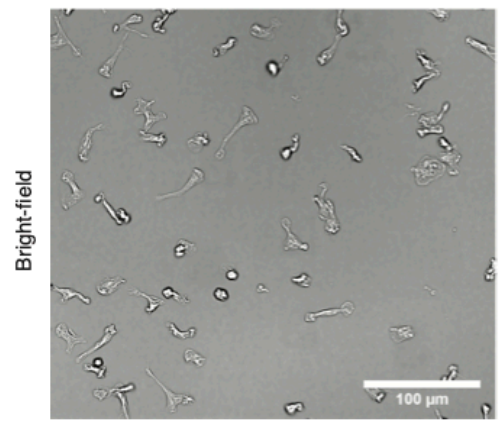

Lower adhesion (Fibronectin $+5 \%$ molar BSA)

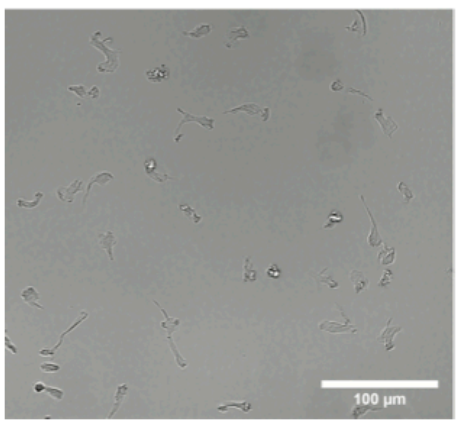

i

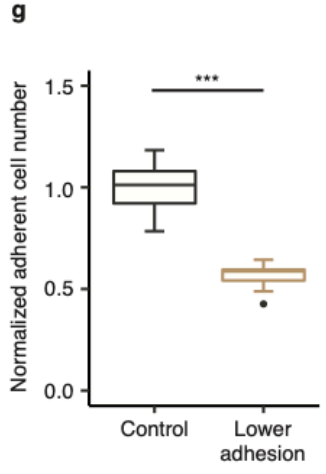

j
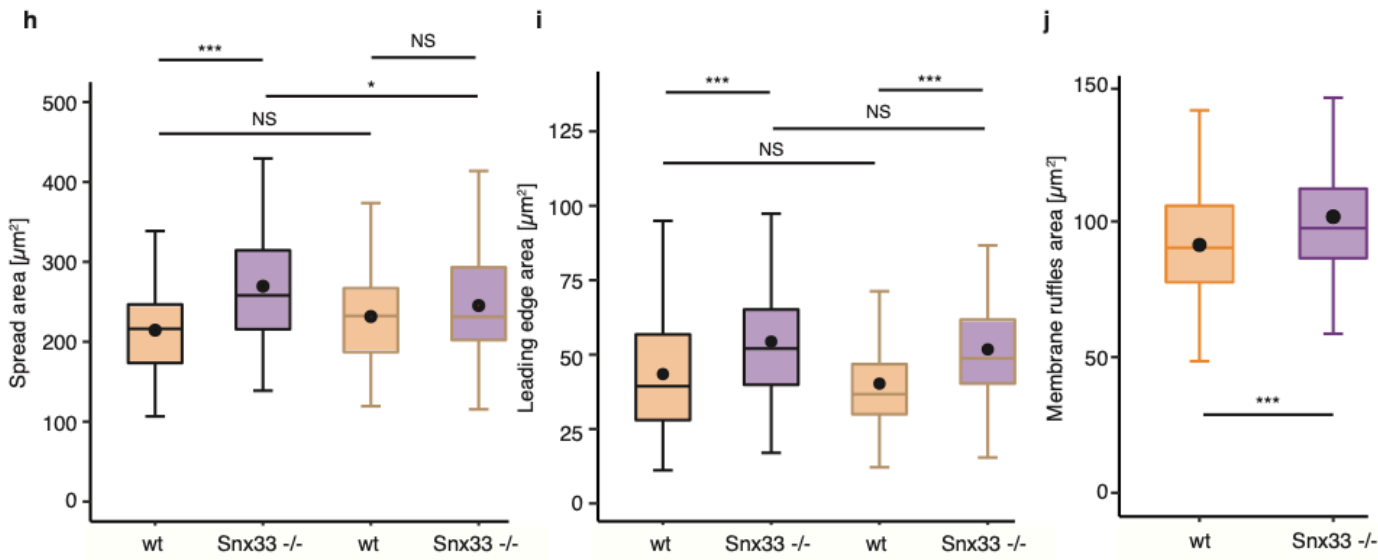

$\bullet$ control

- lower adhesion

$\ominus$ control

$\bullet$ lower adhesion

Supplementary Figure 4: Cell and leading-edge morphology in Snx33 knockout and wt cells. a) Example images of bright-field of wild type, Snx33 -/- and Snx33 -/- with eGFP-tagged Snx33 cells. Quantification of b) cell spread and c) leading edge area. Data from 3 independent experiments. $n=67$ (wt), n=73 (Snx33 -/-), $n=67$ (Snx33 -/- +GFP-Snx33) d) Quantification of cell elongation and e) aspect ratio from TIRFM images. $n=82$ (wt), $n=78$ ( $S n \times 33$ -/-). f) Example bright-field images of wt dHL-60 cells on control (fibronectin only) and lower adhesion substrate (fibronectin with 5\% molar BSA). g) Adhesion-dependent cell number quantification. Data from two independent experiments. Quantification of $h$ ) cell and i) leading edge area. $n=82(w t), n=102$ (Snx33 -/-); Lower adhesion: $\mathrm{n}=53$ (wt), $\mathrm{n}=72$ (Snx33 -/-). j) Quantification of membrane ruffles area in wt and Snx33 -/-dHL-60 cells. $n=175$ (wt), $n=170$ (Snx33 -/-). Statistics: t-test and Mann-Whitney-U- Test. Scale bars $=10 \mu \mathrm{m} . \mathrm{p}<0.001\left(^{(\star \star}\right), p<0.01\left(^{\star \star}\right)$, $\mathrm{p}<0.05\left(^{*}\right)$. 
bioRxiv preprint doi: https://doi.org/10.1101/2021.03.26.437199; this version posted May $16,2021$. The copyright holder for this preprint (which was not certified by peer review) is the author/funder, who has granted bioRxiv a license to display the preprint in perpetuity. It is made available under aCC-BY-NC-ND 4.0 International license.

a

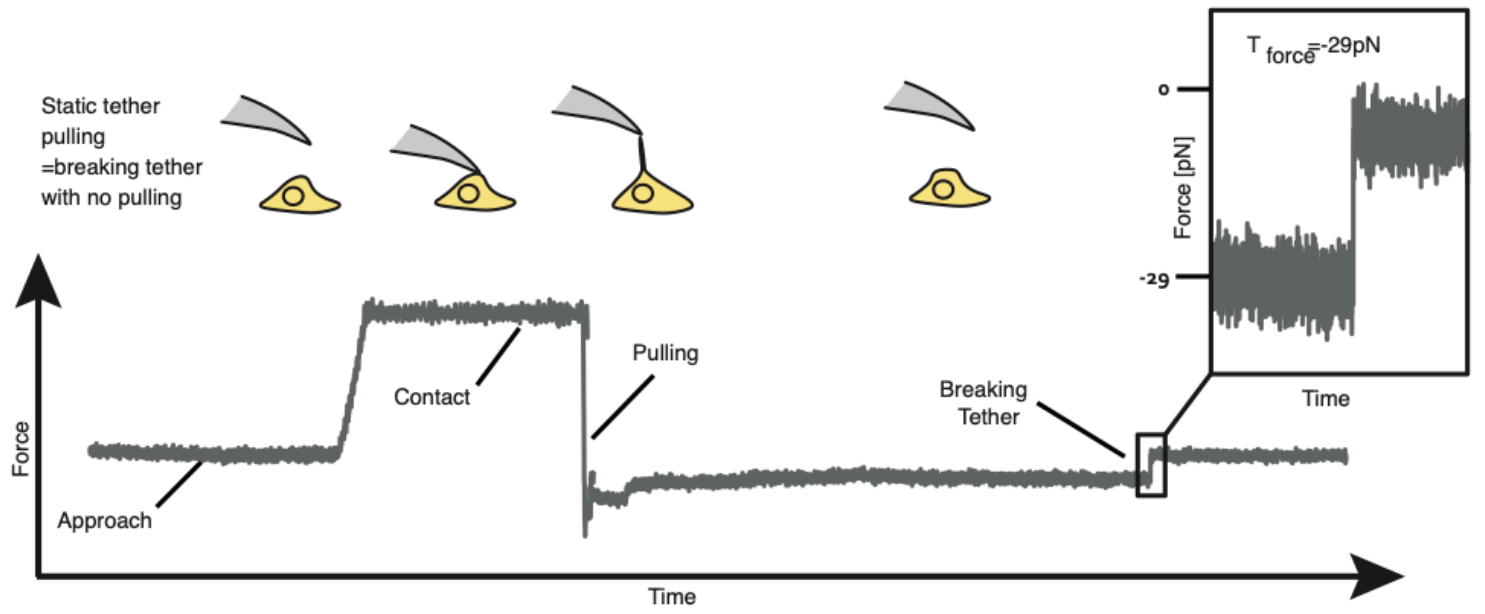

b

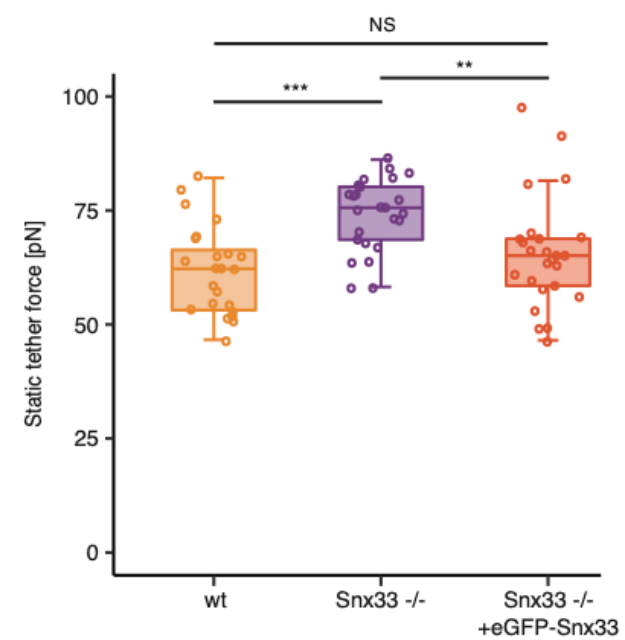

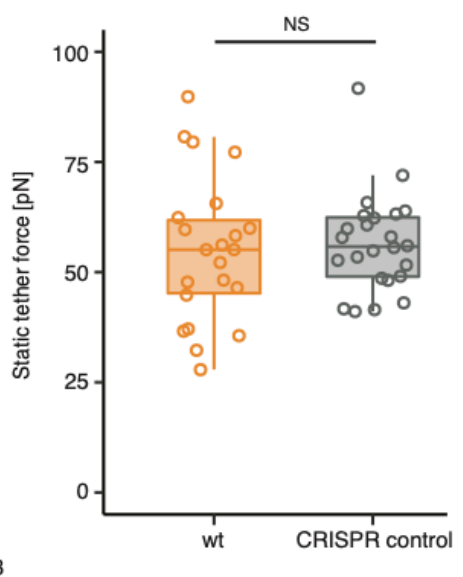

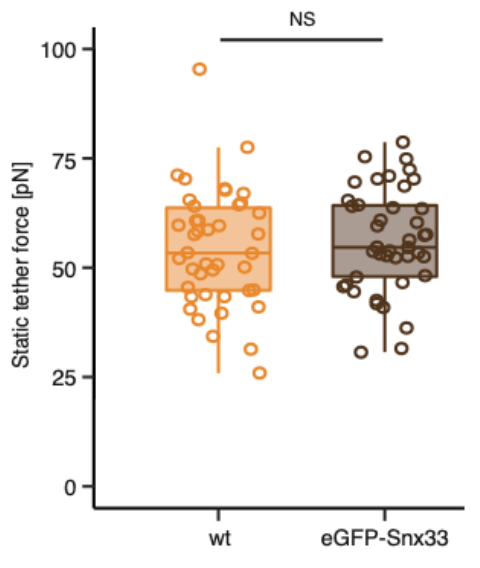

Supplementary Figure 5: Snx33 knockout increases apparent membrane tension. a) Schematic of static tether pulling experiments. b) Mean static tether force of wt $(n=24)$, Snx33 -/- $(n=26)$ and Snx33 -/- with overexpressed eGFP-Snx33 ( $n=25)$ from 3 independent experiments. c) Mean static tether force of wt $(n=27)$ and CRISPR control $(n=28) d H L-60$ cells from 4 independent experiments. d) Mean static tether force of wt $(n=42)$ and eGFPSnx33 over-expressed $(n=42) d H L-60$ cells from 6 independent experiments. Statistics: t-test and Mann-WhitneyU-test. $\left.p<0.001{ }^{* \star *}\right), p<0.01\left(^{\star *}\right), p<0.05\left(^{*}\right)$. 
bioRxiv preprint doi: https://doi.org/10.1101/2021.03.26.437199; this version posted May 16, 2021. The copyright holder for this preprint (which was not certified by peer review) is the author/funder, who has granted bioRxiv a license to display the preprint in perpetuity. It is made available under aCC-BY-NC-ND 4.0 International license.

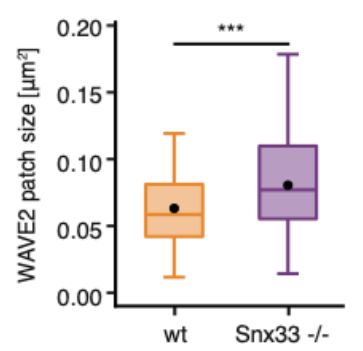

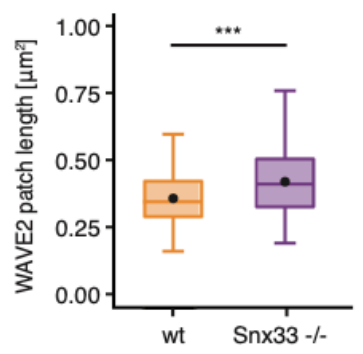
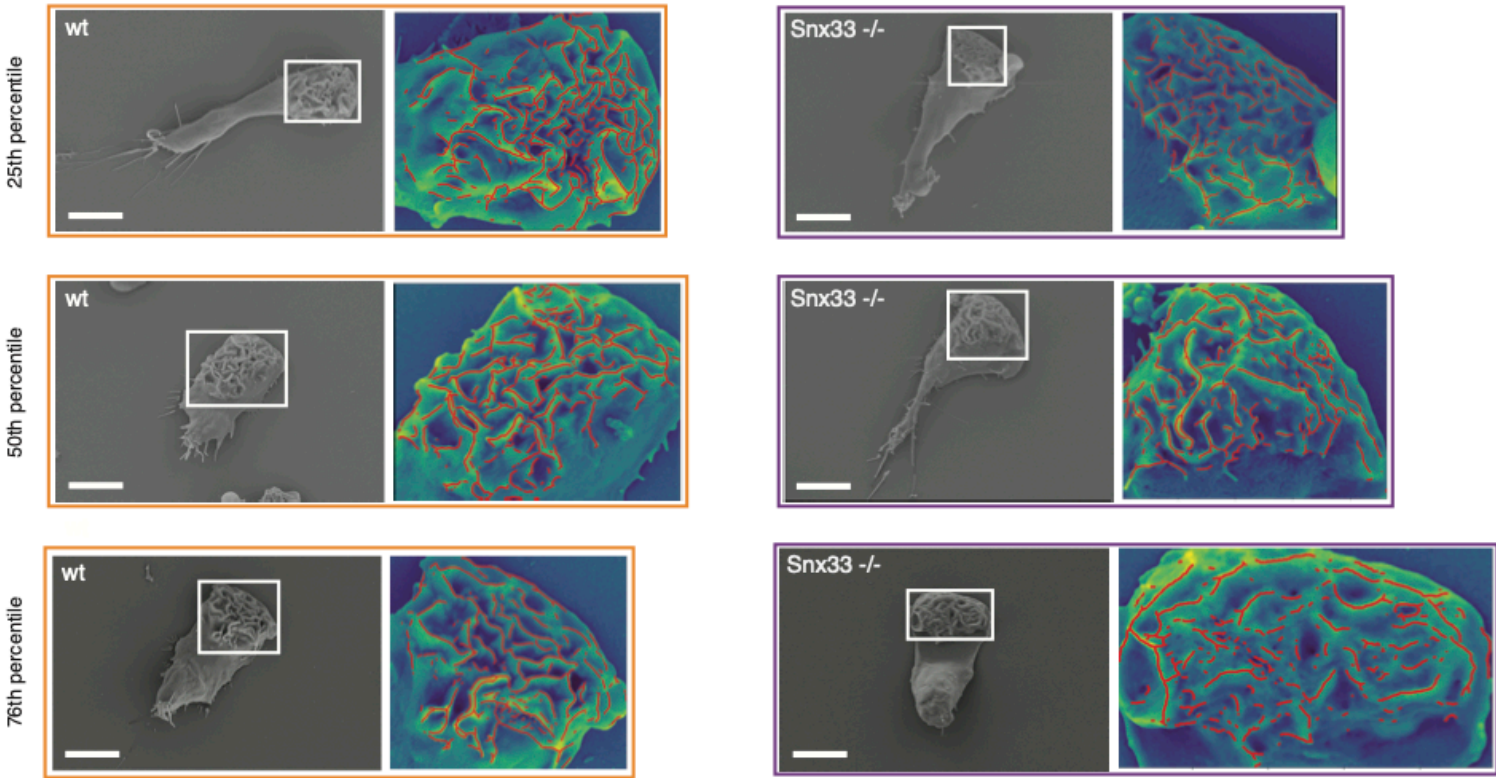

Supplementary Figure 6: WAVE2 pattern size and ruffle wavelength increases in Snx33. a) Quantification of WAVE2 patch size and b) length in wt and Snx33 /- dHL-60 cells. $n=82$ (wt), $n=78$ (Snx33 -/-). c) SEM images (25th, $50^{\text {th }}$ and $76^{\text {th }}$ percentile) with zoom-in of the overlay of the leading-edge and ruffle segmentation (red) for wt and Snx33 -/- dHL-60 cells. Statistics: t-test or nonparametric Mann-Whitney-U-test. Scale bars $\left.=10 \mu \mathrm{m} . \mathrm{p}<0.001{ }^{* * *}\right)$, $\mathrm{p}<0.01\left(^{* *}\right), \mathrm{p}<0.05\left(^{*}\right)$. 
bioRxiv preprint doi: https://doi.org/10.1101/2021.03.26.437199; this version posted May 16, 2021. The copyright holder for this preprint (which was not certified by peer review) is the author/funder, who has granted bioRxiv a license to display the preprint in perpetuity. It is made available under aCC-BY-NC-ND 4.0 International license.

a

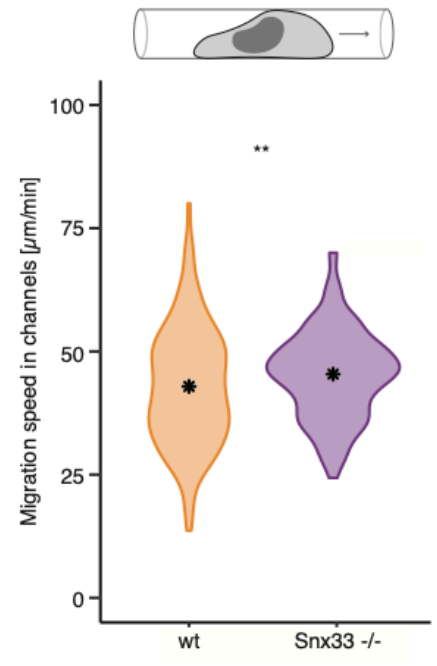

c

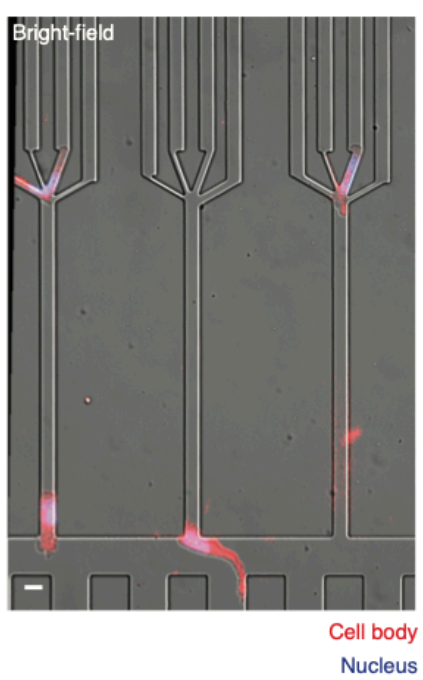

b

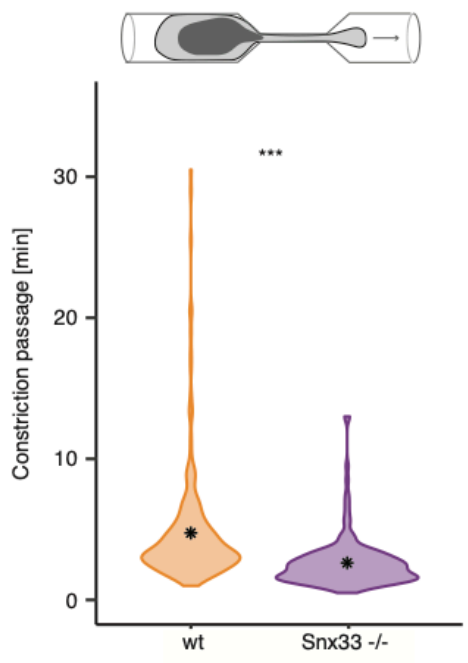

d

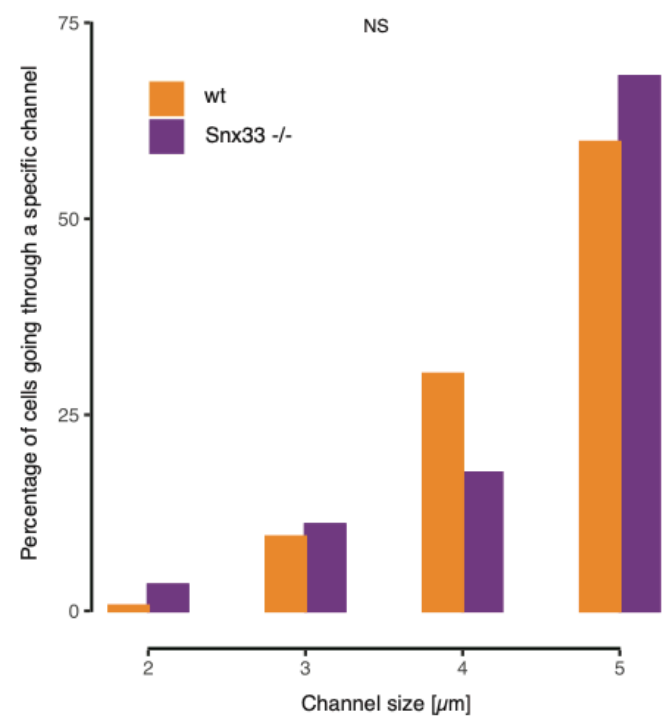

Supplementary Figure 7: Snx33 knockout cells are faster and choose the path of the least resistance. a) Migration speed in straight channels ( $n=235$ for wt, $n=169$ for $S n \times 33-/-)$. b) constriction passage time ( $n=234$ for wt, $\mathrm{n}=158$ for $\mathrm{Sn} \times 33-/-$ ) in dHL-60 cells. c) Overlay of bright-field, nuclei and cell body images of dHL-60 cells migrating in PDMS-based devices with a decision point. d) Frequency of wt and Snx33 - - dHL-60 cells choosing a channel of a certain size ( $n=159$ for wt, $n=91$ for $S n \times 33-/-)$. Data from 3 independent biological replicates. Scale bar $\left.\left.=10 \mu \mathrm{m} . \mathrm{p}<0.001^{(* \star}\right), \mathrm{p}<0.01\left(^{* *}\right), \mathrm{p}<0.05^{*}\right)$. 
bioRxiv preprint doi: https://doi.org/10.1101/2021.03.26.437199; this version posted May 16, 2021. The copyright holder for this preprint (which was not certified by peer review) is the author/funder, who has granted bioRxiv a license to display the preprint in perpetuity. It is made available under aCC-BY-NC-ND 4.0 International license.

a
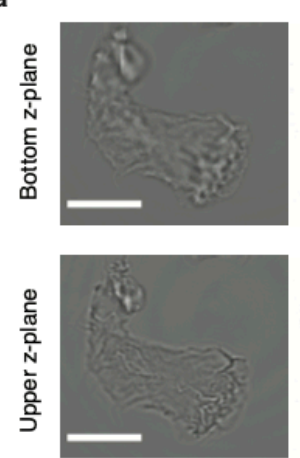

c
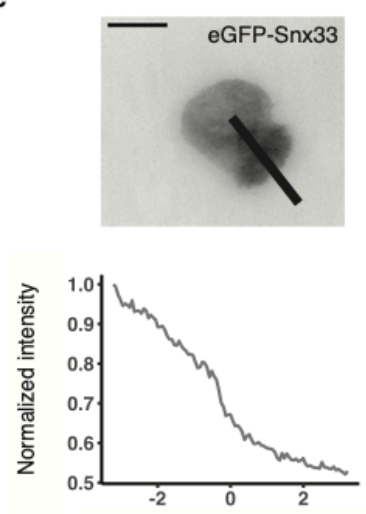

Linescan position $[\mu \mathrm{m}]$
eGFP-Snx33
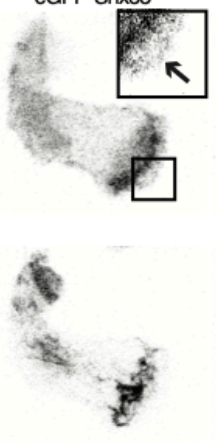

mCherry-Hem 1 eGFP-Snx33+ mCherry-Hem1
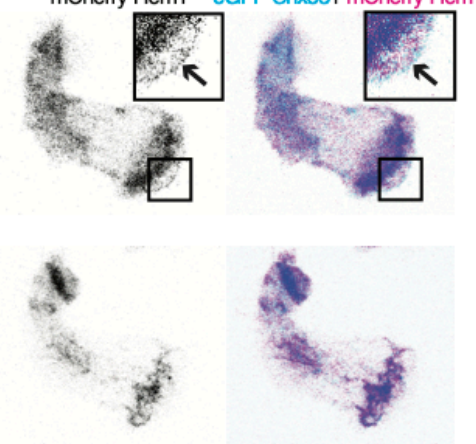

d

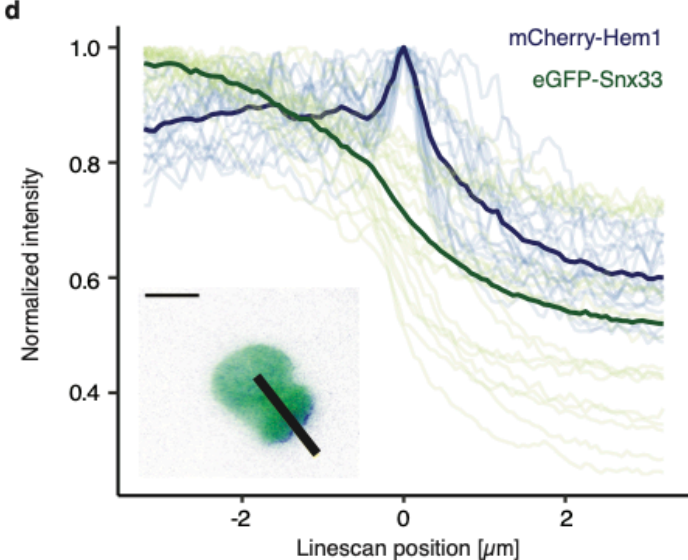

e

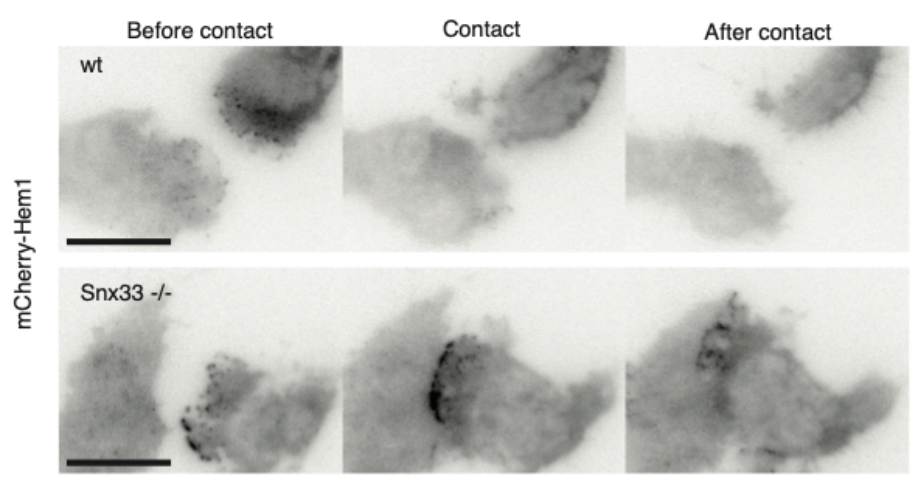

Supplementary Figure 8: Snx33 is excluded from the protruding edge. a) Bright-field and confocal images of dHL-60 cell, eGFP-Snx33 and mCherry-Hem1 (component of WAVE2 complex) in the bottom and upper z-planes. Arrows indicate the most protruding edge at the cell bottom. b) Pearson correlation of eGFP-Snx33 and mCherryHem 1 in normalized $z$-planes in the leading edge. $n=10$. Purple regions denote standard error of the mean. c) Exemplary images of fluorescently-tagged Snx33 and Hem1 and line scans through the leading edge in dHL-60 cells using TIRFM. d) Snx33 and Hem1 normalized intensity at the protrusion edge. e) TIRFM images of Hem1 signal before, during and after the contact event in wt and Snx33 -/- cells. Scale bar $=10 \mu \mathrm{m}$. 


\section{Acknowledgements}

We thank Jan Ellenberg for critical feedback on the manuscript and the Life Science Editors for editing assistance. The plasmid with $\mathrm{hSn \times 33}$ was a kind gift from Duanqing Pei. We thank Brian Graziano for providing protocols, reagents and key advice to generate CRISPR knockout HL-60 cells. We thank Jakub Czuchnowski for advice on image analysis. We thank the EMBL flow cytometry core facility, the EMBL advanced light microscopy facility and the EMBL genomics core facility for support and advice. We thank the EMBL genome biology computational support (and specially Charles Girardot and Jelle Scholtalbers) for critical assistance during RNAseq analysis. We acknowledge the financial support of the European Molecular Biology Laboratory (EMBL) to A.D-M., Y.S. and A.E., the EMBL Interdisciplinary Postdocs (EIPOD) fellowship under Marie Sklodowska-Curie Actions COFUND to M.S.B., the BEST program funding by FCT (SFRH/BEST/150300/2019) to S.D.A. and the Joachim Herz Stiftung Add-on Fellowship for Interdisciplinary Science to E.S.

\section{Author Contributions}

A.D.M., E.S conceived the project and designed the experiments. E.S., M.B. and J.S., performed the experiments with EM advice from Y.S and microfluidic support from M.S.. E.S. and S.D.A. analyzed the data with support from A.E. and A.K.. A.E. performed the theoretical analysis. A.D.M. and E.S and A.E wrote the manuscript. All authors contributed to the interpretation of the data, read and approved the final manuscript.

\section{References}

1. Sarris, M. \& Sixt, M. Navigating in tissue mazes: chemoattractant interpretation in complex environments. Current Opinion in Cell Biology 36, 93-102 (2015).

2. Stoitzner, P., Stössel, H., Romani, N. \& Pfaller, K. A Close-Up View of Migrating Langerhans Cells in the Skin. Journal of Investigative Dermatology 118, 117-125 (2002).

3. Weigelin, B., Bakker, G.-J. \& Friedl, P. Intravital third harmonic generation microscopy of collective melanoma cell invasion: Principles of interface guidance and microvesicle dynamics. Intravital 1, 32-43 (2012).

4. Diz-Muñoz, A. et al. Steering cell migration by alternating blebs and actin-rich protrusions. BMC Biology 113 (2016). doi:10.1186/s12915-016-0294-x

5. Fritz-Laylin, L. K. et al. Actin-based protrusions of migrating neutrophils are intrinsically lamellar and facilitate direction changes. Elife 6, 437 (2017).

6. Leithner, A. et al. Diversified actin protrusions promote environmental exploration but are dispensable for locomotion of leukocytes. Nature Cell Biology 18, 1253-1259 (2016).

7. Baptista, D., Teixeira, L., van Blitterswijk, C., Giselbrecht, S. \& Truckenmüller, R. Overlooked? Underestimated? Effects of Substrate Curvature on Cell Behavior. Trends in Biotechnology 1-17 (2019). doi:10.1016/j.tibtech.2019.01.006

8. Kessels, M. M. \& Qualmann, B. Interplay between membrane curvature and the actin cytoskeleton. Current Opinion in Cell Biology 68, 10-19 (2021).

9. Hoeller, O. et al. G $\beta$ Regulates Coupling between Actin Oscillators for Cell Polarity and Directional Migration. PLoS Biol 14, e1002381 (2016).

10. Weiner, O. D., Marganski, W. A., Wu, L. F., Altschuler, S. J. \& Kirschner, M. W. An actin-based wave generator organizes cell motility. PLoS Biol 5, e221 (2007).

11. Gov, N. S. Guided by curvature: shaping cells by coupling curved membrane proteins and cytoskeletal forces. Philos Trans R Soc Lond B Biol Sci 373, (2018).

12. Reversat, A. et al. Cellular locomotion using environmental topography. Nature 1-21 (2020). doi:10.1038/s41586-020-2283-z

13. Hoogendijk, A. J. et al. Dynamic Transcriptome-Proteome Correlation Networks Reveal Human Myeloid Differentiation and Neutrophil-Specific Programming. Cell Reports 29, 2505-2519.e4 (2019).

14. McMahon, H. T. \& Gallop, J. L. Membrane curvature and mechanisms of dynamic cell membrane remodelling. Nature 438, 590-596 (2005).

15. Simunovic, M., Voth, G. A., Callan-Jones, A. \& Bassereau, P. When Physics Takes Over: BAR Proteins and Membrane Curvature. Trends in Cell Biology 25, 780-792 (2015).

16. Carman, P. J. \& Dominguez, R. BAR domain proteins-a linkage between cellular membranes, signaling pathways, and the actin cytoskeleton. Biophys Rev 10, 1587-1604 (2018).

17. de Kreuk, B.-J. \& Hordijk, P. L. Control of Rho GTPase function by BAR-domains. Small GTPases 3, 4552 (2014).

18. Lacayo, C. I. et al. Emergence of large-scale cell morphology and movement from local actin filament growth dynamics. PLoS Biol 5, e233 (2007).

19. Gauthier, N. C., Fardin, M. A., Roca-Cusachs, P. \& Sheetz, M. P. Temporary increase in plasma membrane tension coordinates the activation of exocytosis and contraction during cell spreading. Proc. Natl. Acad. Sci. U.S.A. 108, 14467-14472 (2011). 
bioRxiv preprint doi: https://doi.org/10.1101/2021.03.26.437199; this version posted May 16,2021 . The copyright holder for this preprint (which was not certified by peer review) is the author/funder, who has granted bioRxiv a license to display the preprint in perpetuity. It is made available under aCC-BY-NC-ND 4.0 International license.

20. Houk, A. R. et al. Membrane tension maintains cell polarity by confining signals to the leading edge during neutrophil migration. Cell 148, 175-188 (2012).

21. Zhang, J., Zhang, X., Guo, Y., Xu, L. \& Pei, D. Sorting nexin 33 induces mammalian cell micronucleated phenotype and actin polymerization by interacting with Wiskott-Aldrich syndrome protein. Journal of Biological Chemistry 284, 21659-21669 (2009).

22. Inagaki, N. \& Katsuno, H. Actin Waves: Origin of Cell Polarization and Migration? Trends in Cell Biology 27, 515-526 (2017).

23. Diz-Muñoz, A. et al. Membrane Tension Acts Through PLD2 and mTORC2 to Limit Actin Network Assembly During Neutrophil Migration. PLoS Biol 14, e1002474-30 (2016).

24. Graziano, B. R. et al. Cell confinement reveals a branched-actin independent circuit for neutrophil polarity. PLoS Biol 17, e3000457 (2019).

25. Krause, M. \& Gautreau, A. Steering cell migration: lamellipodium dynamics and the regulation of directional persistence. Nat Rev Mol Cell Biol 1-14 (2014). doi:10.1038/nrm3861

26. Maiuri, P. et al. Actin Flows Mediate a Universal Coupling between Cell Speed and Cell Persistence. Cell 161, 374-386 (2015).

27. Graziano, B. R. et al. Cell confinement reveals a branched-actin independent circuit for neutrophil polarity. PLoS Biol 17, e3000457-34 (2019).

28. Renkawitz, J. X. R. et al. Nuclear positioning facilitates amoeboid migration along the path of least resistance. Nature 1-29 (2019). doi:10.1038/s41586-019-1087-5

29. Yamada, K. M. \& Sixt, M. Mechanisms of 3D cell migration. Nat Rev Mol Cell Biol 1-15 (2019). doi:10.1038/s41580-019-0172-9

30. Roycroft, A. \& Mayor, R. Molecular basis of contact inhibition of locomotion. Cellular and Molecular Life Sciences 73, 1119-1130 (2015).

31. Stramer, B. \& Mayor, R. Mechanisms and in vivo functions of contact inhibition of locomotion. Nat Rev Mol Cell Biol 18, 43-55 (2016).

32. Ramaswamy, S., Toner, J. \& Prost, J. Nonequilibrium fluctuations, traveling waves, and instabilities in active membranes. Phys. Rev. Lett. 84, 3494-3497 (2000).

33. Gov, N. S. \& Gopinathan, A. Dynamics of Membranes Driven by Actin Polymerization. Biophysical Journal 90, 454-469 (2006).

34. Sens, P. Dynamics of nonequilibrium membrane bud formation. Phys. Rev. Lett. 93, 108103 (2004).

35. Bois, J. S., Jülicher, F. \& Grill, S. W. Pattern formation in active fluids. Physical Review Letters 106, 028103 (2011).

36. Mietke, A., Jülicher, F. \& Sbalzarini, I. F. Self-organized shape dynamics of active surfaces. Proc. Natl. Acad. Sci. U.S.A. 116, 29-34 (2019). 


\section{Methods}

\section{Cell culture}

HL-60 cells were grown in RPMI 1640 media with 10\% heat-inactivated FBS (\#10500-064, Gibco) and $1 \%$ Penicillin-Streptomycin (\#15140-122, Gibco) in a humidified incubator at $37^{\circ} \mathrm{C}$ with $5 \% \mathrm{CO}_{2}$. Cells were differentiated by adding 1.5\% DMSO (\#D2438, Sigma Aldrich) and used after 5 days. Each independently-differentiated batch was treated as a biological replicate. For starvation, cells were kept for 1 hour in FBS-free RPMI 1640 media with $0.3 \%$ fatty acid free BSA (\#A7030-10G, Sigma Aldrich). For imaging or fixation, dHL-60 cells were plated on fibronectin-coated $(0.01 \mathrm{mg} / \mathrm{ml}, \# 356008$, Corning) glass-bottom dishes (\#627860, Greiner bio-one) and allowed to adhere for 10 minutes in growth media. Next, cells were washed and stimulated with $10 \mathrm{nM}$ fMLP (\#F3506-5MG, Sigma Aldrich). For lowering adhesion, the coating was supplemented with 5\% molar BSA (\#A7030-10G, Sigma Aldrich). To generate stable cell lines with fluorescently tagged Snx33, Hem1 and CAAX lentiviral transduction was used as described previously ${ }^{23}$. Cells were sorted on a BD FACS Aria ${ }^{\mathrm{TM}}$ at EMBL Flow Cytometry Core Facility.

\section{Generation of knockout cell line by CRISPR/Cas9}

CRISPR/Cas9 generation in HL-60 cells was performed as described previously ${ }^{24}$. Cloning of the target guide sequence to target $S n \times 33$ was performed as previously described 37,38 (Forward: CACCGctgggacgacGGATGCACAG; Reverse: aaacCTGTGCATCCgtcgtcccagC). Cells expressing BFP-tagged Cas9 were single-cell sorted in 96-well plate on BD FACS AriaTM Fusion at EMBL Flow Cytometry Core Facility. Single-cell clones were verified by genomic DNA amplification by Touchdown $\mathrm{PCR}^{39}$ and sequencing, followed by Western blot of selected clonal lines.

\section{Western blot}

For immunodetection of Snx33 and GAPDH, $6 \times 10^{6}-1.2 \times 10^{7} \mathrm{HL}-60$ cells were lysed in RIPA Lysis and Extraction buffer (\#89900, Thermo ScientificTM) according to manufacturer's instruction with supplementation of the protease inhibitors (\#4693159001, Roche). Samples were denatured with 4xLaemmli buffer (\#161- 0747, BioRad) containing 10\% $\beta$-mercaptoethanol (\#m6250, Sigma Aldrich) at $95^{\circ}$ for $5 \mathrm{~min}$. After SDS-PAGE and transfer, PVDF membrane with transferred proteins was blocked in $5 \%$ BSA in TBST and incubated over-night with 1:1000 dilution of anti-Snx33 (\#orb331346, Biorbyt) or 1:80 000 dilution of anti-GAPDH (\#NB300-221, Novus Biologicals). The blot was developed with secondary antibodies at 1:10 000 dilution of Donkey-Anti-Rabbit-HRP (711-035-152, Jackson Immuno Research) or Goat-Anti-Mouse-HRP (115-035-062, Jackson ImmunoResearch).

\section{CD11b staining of $\mathrm{HL}-60$ cells}

After starvation, $1 \times 10^{5}$ of undifferentiated and differentiated HL-60 cells were stained with Anti-Hu CD11b Alexa Fluor ${ }^{\circledR} 488$ antibody solution (\#A4-681-T100, Exbio). Fluorescence was measured on a Cytek® Aurora (Cytek) at the EMBL Flow Cytometry Core Facility and further analyzed and plotted using FlowJo.

\section{RNA sequencing}

Total RNA samples obtained from 3 biological replicates were purified using RNeasy Mini Kit (\#74104, Qiagen) according the manufacturer instructions with a DNase digestion step (\#79254, Qiagen). To ensure high quality, samples were analyzed on an Agilent 2100 Bioanalyzer (Agilent Technologies). RNA sequencing was performed on an Illumina NextSeq 500 platform as NextSeqHigh-75 SE at the EMBL genomics core facility. For sequence alignment the hg19 reference genome was used. Differential expression analysis was performed with a custom-made Galaxy pipeline using a DESeq2 package.

\section{Imaging}

TIRFM images of live cells were acquired on a Nikon Ti Eclipse inverted microscope with a TIRF objective CFI Plan Apo Lambda 100x Oil (\#MRD01905, Nikon) and SCMOS camera controlled by NISElements (Nikon). Sample drift was reduced using an autofocus system (Perfect Focus, Nikon) for time lapse imaging.

Confocal images of fixed cells were obtained with a silicone objective UPLSAPO 60X S (NA 1.3; WD $0.3 \mathrm{~mm}$ ) on an Olympus FV3000 inverted microscope at EMBL advanced light microscopy facility. 
Epifluorescent and bright-field imaging of fixed cells was performed using a 40x objective (\#MRD00405, Nikon), the SOLA SE II and 100W halogen lamps (Nikon) using appropriate filter sets.

Polarized TIRFM (pTIRFM) modality was implemented based on previous work ${ }^{40-45}$. For imaging, dHL-60 cells were stained before plating with carbocyanine dye Dil (\#D3911, ThermoFisher Scientific).

\section{Fixation and F-actin staining}

Migrating dHL-60 cells were fixed by adding fixation buffer $(2 \mathrm{x})$ to growth media $(1: 1 \mathrm{v} / \mathrm{v})$ and incubated at $4^{\circ} \mathrm{C}$ for 1 hour. Fixation buffer (1x) contains $3.7 \%$ paraformaldehyde (\#28908, Thermo Scientific), 1x intracellular buffer ( $140 \mathrm{mM} \mathrm{KCL}, 1 \mathrm{mM} \mathrm{MgCl}$, 2 mM EGTA, $20 \mathrm{mM}$ HEPES, pH 7.5), $320 \mathrm{mM}$ sucrose (\#S0389-500G, Sigma Aldrich) and 0.2\% BSA (\#A7030-10G, Sigma Aldrich). Cells were washed and stored in $\mathrm{dPBS}$. For permeabilization and staining, cells were re-suspended in intracellular buffer $(1 \mathrm{x})$ containing $0.2 \%$ of Triton X-100 (\#T8787, Sigma Aldrich). If applicable, phalloidin coupled with TRITC (\#P1951, Sigma Aldrich) was added at this step. After washing with dPBS, cells were stored at $4^{\circ} \mathrm{C}$ in the dark or used immediately for imaging.

\section{Theoretical calculations}

Calculations for Fig. 1e and Fig. 3a were performed in Wolfram Mathematica v12.1.1.0. For the details of the derivations please see the Supplementary Note.

\section{Cell migration assays in PDMS-based devices}

PDMS-based microfluidic devices were prepared as previously described $28,46,47$. The devices used for migration of dHL-60 cells had heights of $2.8 \mu \mathrm{m}$ and $3.13 \mu \mathrm{m}$ for channels with decision point and channels with constriction, respectively. The decision channels had constrictions of $2,3,4$ and $5 \mu \mathrm{m}$ in two arrangements. The channels with single constrictions were $2 \mu \mathrm{m}$. To visualize nuclei and cell body, Hoechst 33342 (\#62249, Thermo Fisher Scientific) and TAMRA (Invitrogen) were added before the introduction of cells into the PDMS device. Cell migration towards chemoattractant (fMLP) was imaged on an inverted wide-field Nikon Eclipse microscope using 20x/0.5 PH1 air objective, equipped with a Lumencor light source $(390 \mathrm{~nm}, 475 \mathrm{~nm}, 542 / 575 \mathrm{~nm}$ ), an incubation chamber and the heated stage with $\mathrm{CO}_{2}$. The acquired data were analyzed using ImageJ software and manually curated. Only single cells that moved through the entire channel were considered for analysis. All the parameters were quantified based on the nuclei signal.

\section{Tether extrusion using atomic force spectroscopy}

Apparent membrane tension was measured by extruding plasma membrane tethers. For measurements, Olympus BioLevers $(k=60 \mathrm{pN} / \mathrm{nm})$ from Bruker were mounted on a CellHesion 200 AFM (Bruker), which is integrated into an Eclipse Ti inverted light microscope (Nikon). Cantilevers were calibrated using the thermal noise method and coated with $2.5 \mathrm{mg} / \mathrm{ml}$ Concanavalin A (\#C5275, Sigma Aldrich). Prior to the measurements, cantilevers were rinsed in dPBS. For tether measurement, the cantilever was position over the cell, preferably over the leading edge. Measurements parameters for static tether pulling experiments were as followed: approach velocity was set to $1 \mu \mathrm{m} / \mathrm{s}$, contact force to $100-300 \mathrm{pN}$, contact time to $5-10 \mathrm{~s}$, and retraction speed to $10 \mu \mathrm{m} / \mathrm{s}$. After a $10 \mu \mathrm{m}$ tether was pulled, the cantilever position was held constant until it broke, but no longer than $30 \mathrm{~s}$. In every experimental repetition the conditions' order was randomized. For every cell at least 3 different tether measurements were taken.

The data analysis was performed using the JPK Data Processing Software. For assessing the magnitude of membrane tension based on tether force measurements, the following formula was used 23 :

$$
T=\frac{F_{0}^{2}}{8 B \pi^{2}}
$$

where $F_{0}$ is the tether force measured by the AFM and $B$ is the bending rigidity of the plasma membrane, which we assume to be invariable between different experimental conditions $\left(2.7 \times 10^{-19} \mathrm{Nm}\right.$ based on previous measurements ${ }^{48,49}$ ). 


\section{Image analysis}

For confocal images, only the z-planes that contained the top $80 \%$ intensity of mCherry-CAAX were considered based on line scans covering the entire resliced maximum intensity $z$ projection. A channel of interest (ChoF1) was used for mask generation based on automatic Otsu segmentation. A custommade ImageJ script allowed to calculate the Pearson correlation coefficient (PCC) for every z-plane of ChoF1 with ChoF2 based on the mask of ChoF1 using the in-built Coloc2 ImageJ plugin. Z-slices were assigned to 10 bins and the mean with standard error of the mean for every bin was calculated.

For epifluorescence images, single cells were manually selected using the ImageJ software. To segment the cell body, the contrast of bright-field images was enhanced using the equalize histogram function followed by a canny edge detection, a semi-manual closing of the obtained edges and filling the holes. To segment the leading edge, a similar strategy was used with semi-manual selection of the region with the enriched edges after the canny edge detection with higher values step. Based on the segmentation, a custom Python script was used for measurements.

For analysis of migrating cells imaged by TIRFM, a segmentation of the cell mask (based on mCherry-CAAX signal) and of the WAVE2 mask (based on eGFP-Hem1 signal) were acquired using the machine learning-based ilastik software ${ }^{50}$. Further image analysis was achieved using an in-house built program implemented in Python. The angle at which cells are moving was calculated based on the center of mass for 3 consecutive frames. The leading edge was defined as the difference between two consecutive frames where at least one pixel of WAVE2 mask is present per cluster. Leading edge length was defined as a number of pixels in the outside perimeter of the leading edge. For the analysis of cellcell contacts the same segmentation strategy was used to segment individual cells. Cell-cell contact was defined as the perimeters' intersection of both cells.

For membrane topography analysis of SEM data, the leading edge area with ruffles was manually segmented on median filtered images. Next, ridges were detected within the segmented regions using the Meijering filter ${ }^{51}$. Ridges were later segmented using automatic Otsu thresholding and skeletonized using a custom Python script. Inversion of the number of pixels within the skeletonization per leading edge area corresponds to the effective the ruffle wavelength.

For analysis of signal enrichment at the cell edge based on TIRFM images, data on fluorescent intensity along the line of equal width and length were extracted from both channels of interest (eGFPSnx33, mCherry-Hem1) using ImageJ. Data were aligned according to the highest fluorescence intensity of mCherry-Hem 1 and normalized. Normalized mean intensity was calculated in both channels of interest for every point along the line scan and plotted using $R$.

\section{Scanning electron microscopy}

After 30 min of $10 \mathrm{nM}$ fMLP stimulation, cells were fixed in 2,5\% GA (\#16220, EMS) in 0,1M PHEM buffer by adding $37^{\circ} \mathrm{C}$ double strength fixative (5\% GA in $0,1 \mathrm{M}$ PHEM) directly $1: 1$ to the cell medium. After 10 minutes incubation, the fixative was replaced by fresh single strength fixative and cells were further fixed at room temperature for $1 \mathrm{~h}$. After fixation, cells were washed 2 times in $0,1 \mathrm{M}$ PHEM and 2 times in $0,1 \mathrm{M}$ cacodylate buffer. Next, they were postfixed for $2 \mathrm{~h}$ on ice in freshly prepared and filtered $1 \% \mathrm{OsO}_{4}(\# 19190, \mathrm{EMS})$ and $0,8 \%$ potassium ferrocyanide $\left(\mathrm{K}_{4}\left[\mathrm{Fe}(\mathrm{CN})_{6}\right]^{\star} 3 \mathrm{H}_{2} \mathrm{O}, \# 4984\right.$, Merck) in $0,1 \mathrm{M}$ cacodylate buffer. After postfixation, the cells were washed 4 times in $\mathrm{H}_{2} \mathrm{O}$, and left at $4^{\circ} \mathrm{C}$ until further processing.

Next, cells were treated with freshly prepared and filtered 1\% tannic acid (TA, CAS\#1401-55-4, EMS) in water using a Pelco BioWave microwave for seven 1-minute cycles alternating between $150 \mathrm{~W}$ and $\mathrm{O} \mathrm{W}$ power. Steady temperature was set to $23^{\circ} \mathrm{C}$ and vacuum to on for all steps. After TA treatment, cells were washed $2 x$ in $\mathrm{H}_{2} \mathrm{O}$ on the bench and $2 x$ in $\mathrm{H}_{2} \mathrm{O}$ in the microwave for 40 s per step at $250 \mathrm{~W}$ power. Cells were then treated with $1 \%$ UA (\#77870, Serva) in $\mathrm{H}_{2} \mathrm{O}$ using the same microwave program as for TA. After washing once in $\mathrm{H}_{2} \mathrm{O}$ and twice in $25 \% \mathrm{EtOH}$, cells were dehydrated in a graded series of ethanol $(25 \%-50 \%-75 \%-90 \%-100 \%-100 \%)$ using a microwave program with step length of 40 $\mathrm{s}$ and $250 \mathrm{~W}$ power, with a steady temperature at $4{ }^{\circ} \mathrm{C}$ and without vacuum. Finally, the cells were infiltrated with a graded series of Hexamethyldisilizane (HMDS, CAS\# 999-97-3, Sigma Aldrich) in ethanol $(25 \%-50 \%-75 \%-100 \%-100 \%)$ using a microwave program with 6 steps of 1 minute each, with a power of $150 \mathrm{~W}$ for step 1, 3, 4 and 6, and $0 \mathrm{~W}$ for steps 2 and 5 . After the final $100 \%$ HMDS infiltration, all HMDS was removed, and coverslips were left to dry overnight. Silica gel with moisture indicator (Merck) was added in 4 empty wells (corners) in the 24-well plate to remove excess humidity.

After drying, coverslips were mounted in aluminum stubs (Agar Scientific G301F) using carbon tape, and sputter coated with a layer of gold for $180 \mathrm{~s}$ at $30 \mathrm{~mA}$ current using a Quorum sputter coater model Q150RS. 
bioRxiv preprint doi: https://doi.org/10.1101/2021.03.26.437199; this version posted May $16,2021$. The copyright holder for this preprint (which was not certified by peer review) is the author/funder, who has granted bioRxiv a license to display the preprint in perpetuity. It is made available under aCC-BY-NC-ND 4.0 International license.

Imaging was performed on a Zeiss Crossbean 540 microscope, using $5 \mathrm{kV}$ acceleration voltage and $700 \mathrm{pA}$ current for the electron beam, with a working distance of $5 \mathrm{~mm}$. A secondary electron detector (SESI) was used for signal detection, and all images were acquired with a pixel size of 28,9 $\mathrm{nm} /$ pixel.

\section{Statistical analysis}

Statistical analyses were performed using $R$, while data visualization by both $R$ and Adobe Illustrator ${ }^{\circledR}$. Normality of data distribution was tested by Shapiro-Wilk test. Two-tailed t-test was used for normal distribution. Otherwise, a non-parametric Mann-Whitney-U-test was used, if not indicated differently. In all box-plots, the lower and upper hinges correspond to the first and third quartiles (the 25th and 75th percentiles). The upper whisker extends from the hinge to the largest value, but no further than $1.5^{\star} I Q R$ (distance between the first and third quartiles). The lower whisker extends from the hinge to the smallest value, but no lower than $1.5^{\star}$ IQR of the hinge. Data beyond the end of the whiskers are plotted as black dots. Black line and dot correspond to the median and mean, respectively.

37. Shalem, O. et al. Genome-scale CRISPR-Cas9 knockout screening in human cells. Science 343, 84-87 (2014).

38. Sanjana, N. E., Shalem, O. \& Zhang, F. Improved vectors and genome-wide libraries for CRISPR screening. Nat Meth 1-2 (2014). doi:10.1038/nmeth.3047

39. Koch, B. et al. Generation and validation of homozygous fluorescent knock-in cells using CRISPR-Cas9 genome editing. Nature Publishing Group 13, 1465-1487 (2018).

40. Axelrod, D. Evanescent Excitation and Emission in Fluorescence Microscopy. Biophysical Journal 104, 1401-1409 (2013).

41. Anantharam, A., Onoa, B., Edwards, R. H., Holz, R. W. \& Axelrod, D. Localized topological changes of the plasma membrane upon exocytosis visualized by polarized TIRFM. J Cell Biol 188, 415-428 (2010).

42. Oreopoulos, J., Epand, R. F., Epand, R. M. \& Yip, C. M. Peptide-Induced Domain Formation in Supported Lipid Bilayers: Direct Evidence by Combined Atomic Force and Polarized Total Internal Reflection Fluorescence Microscopy. Biophysical Journal 98, 815-823 (2010).

43. Oreopoulos, J. \& Yip, C. M. Combined scanning probe and total internal reflection fluorescence microscopy. Methods 46, 2-10 (2008).

44. Sund, S. E., Swanson, J. A. \& Axelrod, D. Cell membrane orientation visualized by polarized total internal reflection fluorescence. Biophysical Journal 77, 2266-2283 (1999).

45. Axelrod, D. Chapter 7 - Total Internal Reflection Fluorescence Microscopy. Biophysical Tools for Biologists, Volume Two: In Vivo Techniques 89, 169-221 (Elsevier Inc., 2008).

46. Renkawitz, J., Reversat, A., Leithner, A., Merrin, J. \& Sixt, M. Micro-engineered 'pillar forests' to study cell migration in complex but controlled 3D environments. Biophysical Tools for Biologists, Volume Two: In Vivo Techniques 147, 79-91 (Elsevier Inc., 2018).

47. Kopf, A. et al. Microtubules control cellular shape and coherence in amoeboid migrating cells. J Cell Biol 219, 193-24 (2020).

48. Sens, P. \& Plastino, J. Membrane tension and cytoskeleton organization in cell motility. J Phys Condens Matter 27, 273103 (2015).

49. Hochmuth, F. M., Shao, J. Y., Dai, J. \& Sheetz, M. P. Deformation and flow of membrane into tethers extracted from neuronal growth cones. Biophysical Journal 70, 358-369 (1996).

50. Berg, S. et al. ilastik: interactive machine learning for (bio)image analysis. Nat Meth 16, 1226-1232 (2019).

51. Meijering, E. et al. Design and validation of a tool for neurite tracing and analysis in fluorescence microscopy images. Cytometry A 58, 167-176 (2004). 


\section{Supplementary Note: \\ Curvature-dependent mechanochemical patterning in the lamellipodium}

The lamellipodia of many migrating cells exhibit characteristic patterns of actin activity and membrane curvature. These have been studied in the past predominantly by considering the complex interplay of various actinregulatory molecules. Here we investigate the coupling between actin activity and the mechanics of the plasma membrane as an additional regulatory mechanism of the observed patterning, consistent with experimental results that show a role for curvature sensing BAR proteins in the lamellipodia of migrating cells.

\section{Main equations}

\subsection{Activator equation}

In this section, we derive the main equations of the system. We consider the concentration field $A$ of a generic activator of actin such as WAVE2. Because lamellipodia are thin structures with a dense actin meshwork and an average filament orientation towards the leading edge [5], we neglect variations of $A$ across the thickness of the lamellipodium and assume that diffusive transport of actin regulatory molecules occurs predominantly in the direction of average filament alignment $x$. We consider self-activation of $A$ with a rate constant $k_{\mathrm{A}}$ and introduce the curvature-dependent regulatory term $r_{\mathrm{C}}(C)$. From the continuity equation for the surface concentration of activator molecules, we then obtain the following partial differential equation

$$
\frac{\partial}{\partial t} A(x, t)=k_{\mathrm{A}} A(x, t)+r_{\mathrm{C}}(C(x, t))+D \frac{\partial^{2}}{\partial x^{2}} A(x, t)
$$


in which $D$ denotes the diffusion coefficient along the cell migration axis $x$.

\subsection{Curvature equation}

The curvature $C$ depends on the mechanical properties of the plasma membrane. We consider a Helfrich membrane with a bending rigidity $\kappa$ and surface tension $\gamma$ [1, 3]. In the weak bending approximation and with periodic boundary conditions, the conservation of momentum leads to the following equation for the curvature profile along $x[2,4]$

$$
\kappa \frac{\partial^{2}}{\partial x^{2}} C(x, t)-\gamma C(x, t)=P
$$

in which $P=P_{\text {ext }}-P_{\text {int }}$ denotes the pressure difference between the outside and the inside of the cell. We assume that actin polymerization generates an active pressure field which acts on the membrane from within the cell, and that depends on $A(x, t)$. With this term and introducing the membrane persistence length $\lambda=\sqrt{\kappa / \gamma}$, Eq. 2 reads

$$
\lambda^{2} \frac{\partial^{2}}{\partial x^{2}} C(x, t)-C(x, t)=-\frac{f_{\mathrm{A}}}{\gamma} A(x, t),
$$

in which we denote with $f_{\mathrm{A}}$ the force per activator molecule. We have furthermore assumed that the pressure in the absence of activator molecules is balanced across the membrane.

\section{Regulation in the limit of small curvatures}

Generally, the shape of the regulatory function $r_{\mathrm{C}}(C)$ is unknown and depends on the properties of the curvature-sensing proteins involved. The shape of the dominant BAR protein in our experimental system suggests that curvature sensing is relevant in the regime of small curvatures $C(x, t)=\delta C(x, t)$ (Supplementary Fig. 2). Assuming differentiability of $r_{\mathrm{C}}$ with respect to $C$, we may write a general expansion of the form

$$
r_{\mathrm{C}}(C)=r_{\mathrm{C}}(0)+\left.\frac{\mathrm{d} r_{\mathrm{C}}}{\mathrm{d} C}\right|_{C=0} \delta C+\mathcal{O}\left(\delta C^{2}\right)
$$

Here, the magnitude of the linear coefficient depends on the activity of curvature regulatory proteins. To characterize the curvature-dependent feedback 
on $A$ to linear order, it is useful to define the following rate constant

$$
k_{\mathrm{C}}=\left.\frac{\mathrm{d} r_{\mathrm{C}}}{\mathrm{d} C}\right|_{C=0} \frac{f_{\mathrm{A}}}{\gamma} .
$$

In the following, we assume that no curvature regulation takes place for a completely flat membrane sheet, i.e. $r_{\mathrm{C}}(0)=0$.

\section{Patterning regime}

We now explore the consequences of curvature-regulatory coupling between membrane shape and actin activity by analyzing the stability of the steady state $C=0$ and $A=0$, in which the membrane is flat and no actin activity is present. A small perturbation away from this state can be written as

$$
\delta A=\delta A_{0} \exp (\omega t+\mathrm{i} k x), \quad \delta C=\delta C_{0} \exp (\omega t+\mathrm{i} k x),
$$

in which $k$ is the perturbation wavenumber and $\omega$ the corresponding growth rate. Substituting Eq. 6 into Eqs. 1 and 3 and keeping terms to linear order in the perturbation, we obtain the following dimensionless dispersion relation

$$
\frac{\omega(k)}{k_{\mathrm{A}}}=1+\frac{k_{\mathrm{C}}}{k_{\mathrm{A}}\left(1+k^{2} \lambda^{2}\right)}-k^{2} \lambda_{\mathrm{A}}^{2},
$$

in which we have introduced the diffusion length $\lambda_{\mathrm{A}}=\sqrt{D / k_{\mathrm{A}}}$. Figure 1c shows the stability diagram as a function of the normalized persistence length $\lambda / \lambda_{\mathrm{A}}$ and the curvature coupling constant $k_{\mathrm{C}} / k_{\mathrm{A}}$. For positive coupling, the zeroth mode $k_{0}=0$ is growing over time, describing a uniformly advancing flat sheet in the linearized system. For $k_{\mathrm{C}}<0$, there is a region in which spontaneous patterning occurs, i.e. where $\omega\left(k_{\max }\right)>0$ with $k_{\max }>0$. The critical line of the instability is given by

$$
\frac{k_{\mathrm{C}}^{*}}{k_{\mathrm{A}}}=-\left(\frac{\left(\lambda_{\mathrm{A}}^{2}+\lambda^{2}\right)}{2 \lambda_{\mathrm{A}} \lambda}\right)^{2} .
$$

The pattern wavelength at the maximum is given by

$$
l_{\max }=\frac{2 \pi \lambda}{\sqrt{-\mathrm{i} \sqrt{\frac{k_{\mathrm{C}}}{k_{\mathrm{A}}}} \frac{\lambda}{\lambda_{\mathrm{A}}}-1}} .
$$

Thus, curvature feedback can lead to the spontaneous formation of patterns. The wavelength of the fastest-growing mode increases when the magnitude of the curvature coupling constant $k_{\mathrm{C}}$ decreases (Fig. 3a). 


\section{References}

[1] Brown, F. L. (2008). Elastic modeling of biomembranes and lipid bilayers. Annual Review of Physical Chemistry, 59:685-712.

[2] Deserno, M. (2015). Fluid lipid membranes: From differential geometry to curvature stresses. Chemistry and Physics of Lipids, 185:11-45.

[3] Helfrich, W. (1973). Elastic Properties of Lipid Bilayers: Theory and Possible Experiments. Zeitschrift fur Naturforschung - Section C Journal of Biosciences, 28(11-12):693-703.

[4] Schneider, J. A. (2016). The interplay of cell membrane and cytoskeleton Dissertation. (August 1985).

[5] Svitkina, T. M. (2020). Actin Cell Cortex: Structure and Molecular Organization. Trends in Cell Biology, 30(7):556-565. 